\title{
Iterative algorithms approach to a general system of nonlinear variational inequalities with perturbed mappings and fixed point problems for nonexpansive semigroups
}

Pongsakorn Sunthrayuth and Poom Kumam ${ }^{*}$

\footnotetext{
* Correspondence: poom. kum@kmutt.ac.th

Department of Mathematics, Faculty of Science, King Mongkut's University of Technology Thonburi (KMUTT), Bangmod, Bangkok

10140, Thailand
}

\begin{abstract}
In this paper, we introduce new iterative algorithms for finding a common element of the set of solutions of a general system of nonlinear variational inequalities with perturbed mappings and the set of common fixed points of a one-parameter nonexpansive semigroup in Banach spaces. Furthermore, we prove the strong convergence theorems of the sequence generated by these iterative algorithms under some suitable conditions. The results obtained in this paper extend the recent ones announced by many others.

Mathematics Subject Classification (2010): 47H09, 47J05, 47J25, 49J40, 65J15

Keywords: one-parameter nonexpansive semigroup, perturbed mapping, iterative algorithm, variational inequality, strong convergence, Banach space, common fixed points
\end{abstract}

\section{Introduction}

Variational inequality theory has been studied widely in several branches of pure and applied sciences. Indeed, applications of variational inequalities span as diverse disciplines as differential equations, time-optimal control, optimization, mathematical programming, mechanics, finance, and so on (see, e.g., $[1,2]$ for more details). Note that most of the variational problems include minimization or maximization of functions, variational inequality problems, quasivariational inequality problems, decision and management sciences, and engineering sciences problems. For more details, we recommend the reader [3-8,29-31].

Let $X$ be a real Banach space, and $X^{*}$ be its dual space. The duality mapping $J: X \rightarrow 2^{X^{*}}$ is defined by

$$
J(x)=\left\{f \in X^{*}:\langle x, f\rangle=\|x\|^{2},\|f\|=\|x\|\right\},
$$

where $\langle\cdot, \cdot\rangle$ denotes the duality pairing between $X$ and $X^{*}$. If $X:=H$ is a real Hilbert space, then $J=I$ where $I$ is the identity mapping. It is well known that if $X$ is smooth, then $J$ is single-valued, which is denoted by $j$ (see [9]). 
Let $C$ be a nonempty closed and convex subset of $X$ and $T$ be a self-mapping of $C$. We denote $\rightarrow$ and $\rightarrow$ by strong and weak convergence, respectively. Recall that a mapping $T: C \rightarrow C$ is said to be L-Lipschitzian if there exists a constant $L>0$ such that

$$
\|T x-T y\| \leq L\|x-y\|, \quad \forall x, y \in C .
$$

If $0<L<1$, then $T$ is a contraction and if $L=1$, then $T$ is a nonexpansive mapping. We denote by $\operatorname{Fix}(T)$ the set of all fixed points set of the mapping $T$, i.e., $\operatorname{Fix}(T)=\{x \in$ $C: T x=x\}$.

A mapping $F: C \rightarrow X$ is said to be accretive if there exists $j(x-y) \in J(x-y)$ such that

$$
\langle F x-F y, j(x-y)\rangle \geq 0, \quad \forall x, y \in C .
$$

A mapping $F: C \rightarrow X$ is said to be strongly accretive if there exists a constant $\eta>0$ and $j(x-y) \in J(x-y)$ such that

$$
\langle F x-F y, j(x-y)\rangle \geq \eta\|x-y\|^{2}, \quad \forall x, y \in C .
$$

Remark 1.1. If $X:=H$ is a real Hilbert space, accretive and strongly accretive mappings coincide with monotone and strongly monotone mappings, respectively.

Let $H$ be a real Hilbert space, whose inner product and norm are denoted by $\langle\cdot, \cdot\rangle$ and $\|\cdot\|$, respectively. Let $A$ be a strongly positive bounded linear operator on $H$, that is, there exists a constant $\bar{\gamma}>0$ such that

$$
\langle A x, x\rangle \geq \bar{\gamma}\|x\|^{2}, \quad \forall x \in H .
$$

Remark 1.2. From the definition of operator $A$, we note that a strongly positive bounded linear operator $A$ is a $\|A\|$-Lipschitzian and $\eta$-strongly monotone operator.

Let $C$ be a nonempty closed and convex subset of a real Banach space $X$. Recall that the classical variational inequality is to find $x^{*} \in C$ such that

$$
\left\langle\Psi x^{*}, j\left(x-x^{*}\right)\right\rangle \geq 0, \quad \forall x \in C,
$$

where $\Psi: C \rightarrow X$ is a nonlinear mapping and $j\left(x-x^{*}\right) \in J\left(x-x^{*}\right)$. The set of solution of variational inequality is denoted by $V I(C, \Psi)$. If $X:=H$ is a real Hilbert space, then (1.2) reduces to find $x^{*} \in C$ such that

$$
\left\langle\Psi x^{*}, x-x^{*}\right\rangle \geq 0, \quad \forall x \in C .
$$

A typical problem is to minimize a quadratic function over the set of the fixed points of a nonex-pansive mapping on a real Hilbert space $H$

$$
\min _{x \in C} \frac{1}{2}\langle A x, x\rangle-\langle x, u\rangle,
$$

where $C$ is the fixed point set of a nonexpansive mapping $T$ on $H$ and $u$ is a given point in $H$.

In 2001, Yamada [10] introduced a hybrid steepest descent method for a nonexpansive mapping $T$ as follows:

$$
x_{n+1}=T x_{n}-\mu \lambda_{n} F\left(T x_{n}\right), \quad \forall n \geq 0,
$$


where $F$ is a $\kappa$-Lipschitzian and $\eta$-strongly monotone operator with constants $\kappa, \eta>0$ and $0<\mu<\frac{2 \eta}{\kappa^{2}}$. He proved that if $\left\{\lambda_{n}\right\}$ satisfying appropriate conditions, then the sequence $\left\{x_{n}\right\}$ generated by (1.5) converges strongly to the unique solution of variational inequality

$$
\left\langle F x^{*}, x-x^{*}\right\rangle \geq 0, \quad \forall x \in \operatorname{Fix}(T) .
$$

In 2006, Marino and $\mathrm{Xu}$ [11] introduced and considered the following general iterative method:

$$
x_{n+1}=\alpha_{n} \gamma f\left(x_{n}\right)+\left(I-\alpha_{n} A\right) T x_{n}, \quad \forall n \geq 0,
$$

where $A$ is a strongly positive bounded linear operator on a real Hilbert space $H$. They, proved that, if the sequence $\left\{\alpha_{n}\right\}$ of parameters satisfies appropriate conditions, then the sequence $\left\{x_{n}\right\}$ generated by (1.7) converges strongly to the unique solution of the variational inequality

$$
\left\langle(\gamma f-A) x^{*}, x-x^{*}\right\rangle \leq 0, \quad \forall x \in \operatorname{Fix}(T),
$$

which is the optimality condition for the minimization problem

$$
\min _{x \in C} \frac{1}{2}\langle A x, x\rangle-h(x),
$$

where $C$ is the fixed point set of a nonexpansive mapping $T$ and $h$ is a potential function for $\gamma f$ (i.e., $h^{\prime}(x)=\gamma f(x)$ for all $x \in H$ ).

Recently, Tian [12] combined the iterative method (1.7) with the Yamada's method (1.5) and considered the general iterative method for a nonexpansive mapping $T$ as follows:

$$
x_{n+1}=\alpha_{n} \gamma f\left(x_{n}\right)+\left(I-\alpha_{n} \mu F\right) T x_{n}, \quad \forall n \geq 0 .
$$

Then, he proved that the sequence $\left\{x_{n}\right\}$ generated by (1.10) converges strongly to the unique solution of variational inequality

$$
\left\langle(\gamma f-\mu F) x^{*}, x-x^{*}\right\rangle \leq 0, \quad \forall x \in \operatorname{Fix}(T) .
$$

Let $\Psi_{1}, \Psi_{2}: C \rightarrow X$ be two mappings. Yao et al. [7] considered the following problem of finding $\left(x^{*}, y^{*}\right) \in C \times C$ such that

$$
\left\{\begin{array}{l}
\left\langle\rho_{1} \Psi_{1} y^{*}+x^{*}-y^{*}, j\left(x-x^{*}\right)\right\rangle \geq 0, \forall x \in C, \\
\left\langle\rho_{2} \Psi_{2} x^{*}+y^{*}-x^{*}, j\left(x-y^{*}\right)\right\rangle \geq 0, \forall x \in C,
\end{array}\right.
$$

which is called a general system of nonlinear variational inequalities in Banach spaces, where $\rho_{1}>0$ and $\rho_{2}>0$ are two constants. In particular, if $\rho_{1}=1$ and $\rho_{2}=1$ then problem (1.12) reduces to problem of finding $\left(x^{*}, y^{*}\right) \in C \times C$ such that

$$
\left\{\begin{array}{l}
\left\langle\Psi_{1} y^{*}+x^{*}-y^{*}, j\left(x-x^{*}\right)\right\rangle \geq 0, \forall x \in C, \\
\left\langle\Psi_{2} x^{*}+y^{*}-x^{*}, j\left(x-y^{*}\right)\right\rangle \geq 0, \forall x \in C,
\end{array}\right.
$$

which is defined by Yao et al. [13].

Very recently, Yao et al. [7] introduced an iterative algorithm for solving the problem (1.12). To be more precise, they proved the following theorem. 
Theorem YLKY [7]Let $C$ be a nonempty closed convex subset of a uniformly convex and 2-uniformly smooth Banach space $X$ and let $Q_{C}$ be a sunny nonexpansive retraction from $X$ onto $C$. Let the mappings $\Psi_{1}, \Psi_{2}: C \rightarrow X$ be $\alpha$-inverse-strongly accretive and $\beta$-inverse-strongly accretive, respectively. Let $A: C \rightarrow X$ be a strongly positive linear bounded operator with coefficient $\bar{\gamma}>0$. Let $\Omega:=\operatorname{VI}\left(C, \Psi_{1}\right) \cap \operatorname{VI}\left(C, \Psi_{2}\right)$. For given $x_{0} \in C$, let the sequence $\left\{x_{n}\right\}$ be generated by

$$
\left\{\begin{array}{l}
z_{n}=Q_{C}\left(x_{n}-\rho_{2} \Psi_{2} x_{n}\right), \\
y_{n}=Q_{C}\left(z_{n}-\rho_{1} \Psi_{1} z_{n}\right), \\
x_{n+1}=\beta_{n} x_{n}+\left(1-\beta_{n}\right) Q_{C}\left(I-\alpha_{n} A\right) y_{n}, \quad \forall n \geq 0 .
\end{array}\right.
$$

Suppose that $\left\{\alpha_{n}\right\}$ and $\left\{\beta_{n}\right\}$ are sequences in $[0,1]$ satisfying the following conditions: (C1) $\lim _{n \rightarrow \infty} \alpha_{n}=0$ and $\sum_{n=1}^{\infty} \alpha_{n}=\infty$;

(C2) $0<\lim \inf _{n \rightarrow \infty} \beta_{n} \leq \lim \sup _{n \rightarrow \infty} \beta_{n}<1$.

Then, $\left\{x_{n}\right\}$ converges strongly to $\widehat{x} \in \Omega$ which solves the variational inequality (1.12).

On the other hand, motivated and inspired by the idea of Tian [12] and Yao et al. [7], we consider and introduce the following system of variational inequalities in Banach spaces: Let $C$ be a nonempty closed and convex subset of a Banach space $X$. Let $\Psi_{i}, \Phi_{i}: C \rightarrow X(i=1,2)$ be a mapping. First, we consider the following problem of finding $\left(x^{*}, y^{*}\right) \in C \times C$ such that

$$
\left\{\begin{array}{l}
\left\langle\rho_{1}\left(\Psi_{1}+\Phi_{1}\right) y^{*}+x^{*}-y^{*}, j\left(x-x^{*}\right)\right\} \geq 0, \forall x \in C, \\
\left\langle\rho_{2}\left(\Psi_{2}+\Phi_{2}\right) x^{*}+y^{*}-x^{*}, j\left(x-y^{*}\right)\right\} \geq 0, \forall x \in C,
\end{array}\right.
$$

which is called a general system of nonlinear variational inequalities with perturbed mapping in Banach spaces, where $\rho_{1}>0$ and $\rho_{2}>0$ are two constants. In particular, if $\Phi_{1}=\Phi_{2}=0$ then problem (1.15) reduces to problem (1.12). Further, if $\Phi_{1}=\Phi_{2}=0$ and $\rho_{1}=\rho_{2}=1$ then problem (1.15) reduces to problem (1.13). Second, we introduce iterative algorithms (3.15) below for finding a common element of the set of solutions of a general system of nonlinear variational inequalities with perturbed mappings (1.15) and the set of common fixed points of a one-parameter nonexpansive semigroup in Banach spaces. Furthermore, we show that our iterative algorithm converges strongly to a common element of the two aforementioned sets under some suitable conditions. Our results extend the main result of Tian [12] and Yao et al. [7] and the methods of the proof in this paper are also new and different.

\section{Preliminaries}

Let $U=\{x \in X:\|x\|=1\}$. A Banach space $X$ is said to be strictly convex if $\frac{\|x+y\|}{2}<1$ for all $x, y \in U$ with $x \neq y$. A Banach space $X$ is called uniformly convex if for each $\varepsilon>0$ there is a $\delta>0$ such that for $x, y \in X$ with $\|x\|,\|y\| \leq 1$ and $\|x-y\| \geq \varepsilon,\|x+y\| \leq 2(1-\delta)$ holds. The modulus of covexity of $X$ defined by

$$
\delta_{X}(\epsilon)=\inf \left\{1-\left\|\frac{1}{2}(x+y)\right\|:\|x\|,\|y\| \leq 1,\|x-y\| \geq \epsilon\right\}
$$

for all $\varepsilon \in\left[\begin{array}{l}0 \\ 2\end{array}\right]$. It is known that every uniformly convex Banach space is strictly convex and reflexive [9]. The norm of $X$ is said to be Gâteaux differentiable if the limit 


$$
\lim _{t \rightarrow 0} \frac{\|x+t y\|-\|x\|}{t}
$$

exists for each $x, y \in U$. In this case $X$ is smooth. The norm of $X$ is said to be Fréchet differentiable if for each $x \in U$, the limit (2.1) is attained uniformly for $y \in U$. The norm of $X$ is called uniformly Fréchet differentiable if the limit (2.1) is attained uniformly for $x$, $y \in U$. It is well known that (uniform) Fréchet differentiability of the norm of $X$ implies (uniform) Gâteaux differentiability of the norm of $X$.

Let $\rho_{X}:[0, \infty) \rightarrow[0, \infty)$ be the modulus of smoothness of $X$ defined by

$$
\rho_{X}(\tau)=\sup \left\{\frac{1}{2}(\|x+y\|+\|x-y\|)-1: x \in U,\|y\| \leq \tau\right\} .
$$

A Banach space $X$ is said to be uniformly smooth if $\frac{\rho_{X}(t)}{t} \rightarrow 0$ as $t \rightarrow 0$. Suppose that $q>1$, then $X$ is said to be $q$-uniformly smooth if there exists $c>0$ such that $\rho_{X}(t) \leq c t^{q}$. It is easy to see that if $X$ is $q$-uniformly smooth, then $q \leq 2$ and $X$ is uniformly smooth. It is well known that $X$ is uniformly smooth if and only if the norm of $X$ is uniformly Fréchet differentiable and hence the norm of $X$ is Fréchet differentiable, in particular, the norm of $X$ is Fréchet differentiable. Typical examples of both uniformly convex and uniformly smooth Banach spaces are $L_{p}$, where $p>1$. More precisely, $L_{p}$ is $\min \{p, 2\}$ uniformly smooth for every $p>1$.

Definition 2.1. A one-parameter family $\mathcal{S}=\{T(t): t>0\}$ from $C$ into itself is said to be a nonexpansive semigroup on $C$ if it satisfies the following conditions:

(i) $T(0) x=x$ for all $x \in C$;

(ii) $T(s+t) x=T(s) T(t) x$ for all $x \in C$ and $s, t>0$;

(iii) for each $x \in C$ the mapping $t \mapsto T(t) x$ is continuous;

(iv) $\|T(t) x-T(t) y\| \leq\|x-y\|$ for all $x, y \in C$ and $t>0$.

Remark 2.2. We denote by $\operatorname{Fix}(\mathcal{S})$ the set of all common fixed points of $\mathcal{S}$, that is $\operatorname{Fix}(\mathcal{S}):=\bigcap_{t>0} \operatorname{Fix}(T(t))=\{x \in C: T(t) x=x\}$. We know that $\operatorname{Fix}(\mathcal{S})$ is nonempty if $C$ is bounded [14].

Now, we present the concept of a uniformly asymptotically regular semigroup [15-17].

Definition 2.3. Let $C$ be a nonempty closed and convex subset of a Banach space $X, \mathcal{S}=\{T(t): t>0\}$ be a continuous operator semigroup on $C$. Then $\mathcal{S}$ is said to be uniformly asymptotically regular (in short, u.a.r.) on $C$ if for all $h \geq 0$ and any bounded subset $B$ of $C$ such that

$$
\lim _{t \rightarrow \infty} \sup _{x \in B}\|T(h) T(t) x-T(t) x\|=0 .
$$

The nonexpansive semigroup $\left\{\sigma_{t}: t>0\right\}$ defined by the following lemma is an example of u.a.r. operator semigroup. Other examples of u.a.r. operator semigroup can be found in [15].

Lemma 2.4. [18] Let $C$ be a nonempty closed and convex subset of a uniformly convex Banach space $X, B$ be a bounded closed and convex subset of $C$. If we denote $\mathcal{S}=\{T(t): t>0\}$ is a nonexpansive semi-group on $C$ such that $\operatorname{Fix}(\mathcal{S})=\bigcap_{t>0} \operatorname{Fix}(T(t)) \neq \emptyset$. For all $h \geq 0$, the set $\sigma_{t}(x)=\frac{1}{t} \int_{0}^{t} T(s) x \mathrm{~d} s$, then 


$$
\lim _{t \rightarrow \infty} \sup _{x \in B}\left\|\sigma_{t}(x)-T(h) \sigma_{t}(x)\right\|=0 .
$$

Example 2.5. The set $\left\{\sigma_{t}: t>0\right\}$ defined by Lemma 2.4 is u.a.r. nonexpansive semigroup. In fact, it is obvious that $\left\{\sigma_{t}: t>0\right\}$ is a nonexpansive semigroup. For each $h>0$, we have

$$
\begin{aligned}
\left\|\sigma_{t}(x)-\sigma_{h} \sigma_{t}(x)\right\| & =\left\|\sigma_{t}(x)-\frac{1}{h} \int_{0}^{h} T(s) \sigma_{t}(x) \mathrm{d} s\right\| \\
& =\left\|\frac{1}{h} \int_{0}^{h}\left(\sigma_{t}(x)-T(s) \sigma_{t}(x)\right) \mathrm{d} s\right\| \\
& \leq \frac{1}{h} \int_{0}^{h}\left\|\sigma_{t}(x)-T(s) \sigma_{t}(x)\right\| \mathrm{d} s .
\end{aligned}
$$

By Lemma 2.4, we obtain that

$$
\lim _{t \rightarrow \infty} \sup _{x \in B}\left\|\sigma_{t}(x)-\sigma_{h} \sigma_{t}(x)\right\| \leq \frac{1}{h} \int_{0}^{h} \lim _{t \rightarrow \infty} \sup _{x \in B}\left\|\sigma_{t}(x)-T(s) \sigma_{t}(x)\right\| \mathrm{d} s=0 .
$$

Let $D$ be a nonempty subset of $C$. A mapping $Q: C \rightarrow D$ is said to be sunny [19] if

$$
Q(Q x+t(x-Q x))=Q x,
$$

whenever $Q x+t(x-Q x) \in C$ for $x \in C$ and $t \geq 0$. A mapping $Q: C \rightarrow D$ is said to be retraction if $Q x=x$ for all $x \in D$. Furthermore, $Q$ is a sunny nonexpansive retraction from $C$ onto $D$ if $Q$ is a retraction from $C$ onto $D$ which is also sunny and nonexpansive. A subset $D$ of $C$ is called a sunny nonexpansive retraction of $C$ if there exists a sunny nonexpansive retraction from $C$ onto $D$. It is well known that if $X:=H$ is a real Hilbert space, then a sunny nonexpansive retraction $Q_{C}$ is coincident with the metric projection from $X$ onto $C$. The following lemmas concern the sunny nonexpansive retraction.

Lemma 2.6. [19] Let $C$ be a closed and convex subset of a smooth Banach space $X$. Let $D$ be a nonempty subset of $C$. Let $Q: C \rightarrow D$ be a retraction and let $J$ be the normalized duality mapping on $X$. Then the following are equivalent:

(a) $Q$ is sunny and nonexpansive.

(b) $\|Q x-Q y\|^{2} \leq\langle x-y, J(Q x-Q y)\rangle, \forall x, y \in C$.

(c) $\langle x-Q x, J(y-Q x)\rangle \leq 0, \forall x \in C, y \in D$.

Lemma 2.7. [20]If $X$ is a strictly convex and uniformly smooth Banach space and if $T: C \rightarrow C$ is a nonexpansive mapping having a nonempty fixed point set $\operatorname{Fix}(T)$, then the set $\operatorname{Fix}(T)$ is a sunny nonexpansive retraction of $C$.

Let $\mathbb{N}$ be the set of positive integers and let $l^{\infty}$ be the Banach space of bounded valued functions on $\mathbb{N}$ with supremum norm. Let LIM be a linear continuous functional on $l^{\infty}$ and let $x=\left(a_{1}, a_{2}, \ldots\right) \in l^{\infty}$. Then sometimes, we denote by $\operatorname{LIM}_{n}\left(a_{n}\right)$ the value of $\operatorname{LIM}(x)$. We know that there exists a linear continuous functional LIM on $l^{\infty}$ such that $\operatorname{LIM}=\operatorname{LIM}(1)=1$ and $\operatorname{LIM}\left(a_{n}\right)=\operatorname{LIM}\left(a_{n+1}\right)$ for each $x=\left(a_{1}, a_{2}, \ldots\right) \in l^{\infty}$. Such a LIM is called a Banach limit. Let LIM be a Banach limit. Then

$$
\liminf _{n \rightarrow \infty} a_{n} \leq \operatorname{LIM}(x) \leq \lim \sup _{n \rightarrow \infty} a_{n}
$$


Let $l^{\infty}$ be a Banach space of all bounded real-valued sequences. A Banach limit $\operatorname{LIM}_{n}$ [9] is a linear continuous functional on $l^{\infty}$ such that

$$
\text { ||LIM } \mid=1, \quad \liminf \operatorname{in}_{n \rightarrow \infty} a_{n} \leq \operatorname{LIM}_{n} a_{n} \leq \lim \sup _{n \rightarrow \infty} a_{n},
$$

for each $x=\left(a_{1}, a_{2}, \ldots\right) \in l^{\infty}$. Specially, if $a_{n} \rightarrow a$, then $\operatorname{LIM}(x)=a$ [9].

In order to prove our main results, we need the following lemmas.

Lemma 2.8. [21] Let $X$ be a real 2-uniformly smooth Banach space with the best smoothness constant $K>0$. Then the following inequality holds:

$$
\|x+y\|^{2} \leq\|x\|^{2}+2\langle y, J x\rangle+2\|K y\|^{2}, \quad \forall x, y \in X .
$$

Lemma 2.9. [22]In a real Banach space $X$, the following inequality holds:

$$
\|x+y\|^{2} \leq\|x\|^{2}+2\langle y, j(x+y)\rangle, \quad \forall x, y \in X
$$

where $j(x+y) \in J(x+y)$.

Lemma 2.10. [23] Let $\left\{x_{n}\right\}$ and $\left\{l_{n}\right\}$ be bounded sequences in a Banach space $X$ and let $\left\{\beta_{n}\right\}$ be a sequence in $[0,1]$ with $0<\lim _{\inf _{n \rightarrow \infty}} \beta_{n} \leq \lim _{\sup _{n \rightarrow \infty}} \beta_{n}<1$. Suppose $x_{n+1}=$ $\left(1-\beta_{n}\right) l_{n}+\beta_{n} x_{n}$ for all integers $n \geq 0$ and $\lim \sup _{n \rightarrow \infty}\left(|| l_{n+1}-l_{n} \|-|| x_{n+1}-x_{n}||\right) \leq 0$. Then, $\lim _{n \rightarrow \infty}|| l_{n}-x_{n}||=0$.

Lemma 2.11. [24] Let $C$ be a closed and convex subset of a strictly convex Banach space $X$. Let $T_{1}$ and $T_{2}$ be two nonexpansive mappings from $C$ into itself with $\operatorname{Fix}\left(T_{1}\right) \cap \operatorname{Fix}\left(T_{2}\right)=\varnothing$. Define a mapping $S$ by

$$
S x=\delta T_{1} x+(1-\delta) T_{2} x, \quad \forall x \in C,
$$

where $\delta$ is a constant in $(0,1)$. Then $S$ is nonexpansive and $\operatorname{Fix}(S)=\operatorname{Fix}\left(T_{1}\right) \cap \operatorname{Fix}\left(T_{2}\right)$. Lemma 2.12. [9] Let $C$ be a closed and convex subset of a reflexive Banach space $X$. Let $\mu$ be a proper convex lower semicontinuous function of $C$ into $(-\infty, \infty]$ and suppose that $\mu\left(x_{n}\right) \rightarrow \infty$ as $\left\|x_{n}\right\| \rightarrow \infty$. Then, there exists $z \in C$ such that $\mu(z)=\inf _{x \in C}\{\mu(x): x \in C\}$.

Lemma 2.13. [25] Let $C$ be a nonempty closed convex subset of a smooth Banach space $X$ and let $\mathcal{S}=\{T(h): h>0\}$ be a u.a.r. nonexpansive semigroup on $C$ such $\operatorname{Fix}(\mathcal{S})=\cap_{h>0} \operatorname{Fix}(T(h)) \neq \emptyset$ and at least there exists a $T(h)$ which is demicompact. Then, for each $x \in C$, there exists a sequence $\left\{T\left(t_{k}\right): t_{k}>0, k \in \mathbb{N}\right\} \subset\{T(h): h>0\}$ such that $\left\{T\left(t_{k}\right) x\right\}$ converges strongly to some point in $\operatorname{Fix}(\mathcal{S})$, where $\lim _{k \rightarrow \infty} t_{k}=\infty$.

Lemma 2.14. [26] Let $C$ be a nonempty closed and convex subset of a real uniformly convex Banach space and $T: C \rightarrow C$ be a nonexpansive mapping such that $\operatorname{Fix}(T) \neq \varnothing$ . Then, $I-T$ is demiclosed at zero.

Lemma 2.15. [27] Let $X$ be a real smooth and uniformly convex Banach space and let $r>0$. Then there exists a strictly increasing, continuous and convex function $g:[0$, $2 r] \rightarrow \mathbb{R}$ such that $g(0)=0$ and

$$
g(\|x-y\|) \leq\|x\|^{2}-2\langle x, j y\rangle+\|y\|^{2}, \quad \forall x, y \in B_{r} .
$$

Lemma 2.16. [28]Assume that $\left\{a_{n}\right\}$ is a sequence of nonnegative real numbers such that

$$
a_{n+1} \leq\left(1-\sigma_{n}\right) a_{n}+\delta_{n}
$$

where $\left\{\sigma_{n}\right\}$ is a sequence in $(0,1)$ and $\left\{\delta_{n}\right\}$ is a sequence in $\mathbb{R}$ such that

(i) $\sum_{n=0}^{\infty} \sigma_{n}=\infty$;

(ii) $\lim \sup _{n \rightarrow \infty} \frac{\delta_{n}}{\sigma_{n}} \leq 0$ or $\sum_{n=0}^{\infty}\left|\delta_{n}\right|<\infty$. 
Then, $\lim _{n \rightarrow \infty} a_{n}=0$.

Lemma 2.17. Let $C$ be a nonempty closed and convex subset of a real 2-uniformly smooth Banach space $X$. Let $F: C \rightarrow X$ be a $\kappa$-Lipschitzian and $\eta$-strongly accretive operator with constants $\kappa, \eta>0$. Let $0<\mu<\frac{\eta}{\kappa^{2} K^{2}}$ and $\tau=\mu\left(\eta-\mu \kappa^{2} K^{2}\right)$. Then, for each $t \in\left(0, \min \left\{1, \frac{1}{2 \tau}\right\}\right)$, the mapping $S: C \rightarrow C$ defined by $S:=(I-t \mu F)$ is contractive with a constant $1-t \tau$.

Proof. Since $0<\mu<\frac{\eta}{\kappa^{2} K^{2}}$ and $t \in\left(0, \min \left\{1, \frac{1}{2 \tau}\right\}\right)$. This implies that $1-t \tau \in(0$, 1). From Lemma 2.8, for all $x, y \in C$, we have

$$
\begin{aligned}
\|S x-S y\|^{2} & =\|(I-t \mu F) x-(I-t \mu F) y\|^{2} \\
& =\|x-y-t \mu(F x-F y)\|^{2} \\
& \leq\|x-y\|^{2}-2 t \mu\langle F x-F y, j(x-\gamma)\rangle+2 t^{2} \mu^{2} K^{2}\|F x-F y\|^{2} \\
& \leq\|x-y\|^{2}-2 t \mu \eta\|x-y\|^{2}+2 t^{2} \mu^{2} \kappa^{2} K^{2}\|x-y\|^{2} \\
& \leq\left[1-2 t \mu\left(\eta-\mu \kappa^{2} K^{2}\right)\right]\|x-y\|^{2} \\
& \leq\left[1-t \mu\left(\eta-\mu \kappa^{2} K^{2}\right)\right]^{2}\|x-y\|^{2} \\
& =(1-t \tau)^{2}\|x-y\|^{2} .
\end{aligned}
$$

It follows that

$$
\|S x-S y|| \leq(1-t \tau)\| x-y \| .
$$

Hence, we have $S:=(I-t \mu F)$ is contractive with a constant $1-t \tau$. This proof is complete.

Lemma 2.18. Let $C$ be a nonempty closed and convex subset of a real 2-uniformly smooth and uniformly convex Banach space $X$. Let the mappings $\Psi, \Phi: C \rightarrow H$ be $\widetilde{\beta}$-inverse strongly accretive and $\tilde{\gamma}$-inverse strongly accretive, respectively. Then, we have

$$
\|(I-\rho(\Psi+\Phi)) x-(I-\rho(\Psi+\Phi)) y\|^{2} \leq\|x-y\|^{2}+4 \rho^{2} K^{2}\left(\rho-\frac{\widetilde{\beta}}{2 K^{2}}\right)\|\Psi x-\Psi y\|^{2}+4 \rho K^{2}\left(\rho-\frac{\tilde{\gamma}}{2 K^{2}}\right)\|\Phi x-\Phi y\|^{2} .
$$

In particular, if $0<\rho<\min \left\{\frac{\widetilde{\beta}}{2 K^{2}}, \frac{\tilde{\gamma}}{2 K^{2}}\right\}$, then $I-\rho(\Psi+\Phi)$ is nonexpansive.

Proof. By the convexity of $\|\cdot\|^{2}$ and Lemma 2.8, for all $x, y \in C$, we have

$$
\begin{aligned}
\|(I-\rho(\Psi+\Phi)) x-(I-\rho(\Psi+\Phi)) y\|^{2}= & \|x-y-\rho[(\Psi+\Phi) x-(\Psi+\Phi) y]\|^{2} \\
= & \left\|\frac{1}{2}[x-y-2 \rho(\Psi x+\Phi y)]+\frac{1}{2}[x-y-2 \rho(\Phi x-\Phi y)]\right\|^{2} \\
\leq & \frac{1}{2}\|x-\gamma-2 \rho(\Psi x-\Psi y)\|^{2}+\frac{1}{2}\|x-y-2 \rho(\Phi x-\Phi y)\|^{2} \\
\leq & \frac{1}{2}\left[\|x-y\|^{2}-4 \rho\langle\Psi x-\Psi y, j(x-y)\rangle+8 \rho^{2} K^{2}\|\Psi x-\Psi y\|^{2}\right] \\
& +\frac{1}{2}\left[\|x-y\|^{2}-4 \rho\langle\Phi x-\Phi y, j(x-\gamma)\rangle+8 \rho^{2} K^{2}\|\Phi x-\Phi y\|^{2}\right] \\
\leq & \frac{1}{2}\left[\|x-y\|^{2}-4 \rho \widetilde{\beta}\|\Psi x-\Psi y\|^{2}+8 \rho^{2} K^{2}\|\Psi x-\Psi y\|^{2}\right] \\
& +\frac{1}{2}\left[\|x-y\|^{2}-4 \rho \widetilde{\gamma}\|\Phi x-\Phi y\|^{2}+8 \rho^{2} K^{2}\|\Phi x-\Phi y\|^{2}\right] \\
= & \|x-y\|^{2}+4 \rho K^{2}\left(\rho-\frac{\widetilde{\beta}}{2 K^{2}}\right)\|\Psi x-\Psi y\|^{2} \\
& +4 \rho K^{2}\left(\rho-\frac{\widetilde{\gamma}}{2 K^{2}}\right)\|\Phi x-\Phi y\|^{2} .
\end{aligned}
$$


It is clear that, if $0<\rho<\min \left\{\frac{\widetilde{\beta}}{2 K^{2}}, \frac{\tilde{\gamma}}{2 K^{2}}\right\}$, then $I-\rho(\Psi+\Phi)$ is nonexpansive. This proof is complete.

Lemma 2.19. Let $C$ be a nonempty closed and convex subset of a real 2-uniformly smooth and uniformly convex Banach space $X$. Let $Q_{C}$ be a sunny nonexpansive retraction from $X$ onto C. Let $\Psi_{i}: C \rightarrow H(i=1,2)$ be $\widetilde{\beta}_{i}$-inverse-strongly accretive and $\Phi_{i}$ : $C \rightarrow H(i=1,2)$ be $\tilde{\gamma}_{i}$-inverse-strongly accretive. Let $G: C \rightarrow C$ be the mapping defined by

$$
G x:=Q_{C}\left[Q_{C}\left(x-\rho_{2}(\Psi+\Phi) x\right)-\rho_{1}\left(\Psi_{1}+\Phi_{1}\right) Q_{C}\left(x-\rho_{2}\left(\Psi_{2}+\Phi_{2}\right) x\right)\right], \quad \forall x \in C .
$$

If $0<\rho_{1}<\min \left\{\frac{\widetilde{\beta}_{1}}{2 K^{2}}, \frac{\tilde{\gamma}_{1}}{2 K^{2}}\right\}$ and $0<\rho_{2}<\min \left\{\frac{\widetilde{\beta}_{2}}{2 K^{2}}, \frac{\tilde{\gamma}_{2}}{2 K^{2}}\right\}$, then $G: C \rightarrow C$ is nonexpansive.

Proof. By Lemma 2.18, for all $x, y \in C$, we have

$$
\begin{aligned}
\|G x-G y\|= & \| Q_{C}\left[Q_{C}\left(x-\rho_{2}(\Psi+\Phi) x\right)-\rho_{1}\left(\Psi_{1}+\Phi_{1}\right) Q_{C}\left(x-\rho_{2}\left(\Psi_{2}+\Phi_{2}\right) x\right)\right] \\
& -Q_{C}\left[Q_{C}\left(y-\rho_{2}(\Psi+\Phi) y\right)-\rho_{1}\left(\Psi_{1}+\Phi_{1}\right) Q_{C}\left(y-\rho_{2}\left(\Psi_{2}+\Phi_{2}\right) y\right)\right] \| \\
& \leq\left\|\left(I-\rho_{1}\left(\Psi_{1}+\Phi_{1}\right)\right) Q_{C}\left(I-\rho_{2}\left(\Psi_{2}+\Phi_{2}\right)\right) x-\left(I-\rho_{1}\left(\Psi_{1}+\Phi_{1}\right)\right) Q_{C}\left(I-\rho_{2}\left(\Psi_{2}+\Phi_{2}\right)\right) y\right\| \\
& \leq\left\|Q_{C}\left(I-\rho_{2}\left(\Psi_{2}+\Phi_{2}\right)\right) x-Q_{C}\left(I-\rho_{2}\left(\Psi_{2}+\Phi_{2}\right)\right)\right\| \\
& \leq\left\|\left(I-\rho_{2}\left(\Psi_{2}+\Phi_{2}\right)\right) x-\left(I-\rho_{2}\left(\Psi_{2}+\Phi_{2}\right)\right)\right\| \\
& \leq\|x-\gamma\|,
\end{aligned}
$$

which implies that $G: C \rightarrow C$ is nonexpansive. This proof is complete.

Lemma 2.20. Let $C$ be a nonempty closed and convex subset of a real 2-uniformly smooth and uniformly convex Banach space $X . L_{C}$ Let $Q_{C}$ be a sunny nonexpansive retraction from $X$ onto C. Let $\Psi_{i}: C \rightarrow H(i=1,2)$ be $\widetilde{\beta}_{i}$-inverse-strongly accretive and $\Phi_{i}$ : $C \rightarrow H(i=1,2)$ be $\tilde{\gamma}_{i}$-inverse-strongly accretive. For given $\left(x^{*}, y^{*}\right) \in C \times C$ is a solution of the problem (1.15) if and only if $x^{*} \in \operatorname{Fix}(G)$ and $y^{*}=Q_{C}\left(x^{*}-\rho_{2}\left(\Psi_{2}+\Phi_{2}\right) x^{*}\right)$, where $G$ is the mapping defined as in Lemma 2.19.

Proof. Let $\left(x^{*}, y^{*}\right) \in C \times C$ be a solution of the problem (1.15). Then, we can rewrite (1.15) as

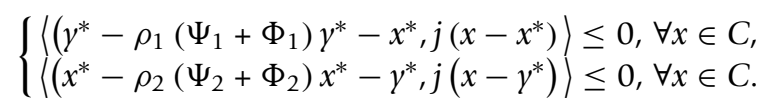

From Lemma 2.6(c), we can deduce that (2.2) is equivalent to

$$
\left\{\begin{array}{l}
x^{*}=Q_{C}\left(y^{*}-\rho_{1}\left(\Psi_{1}+\Phi_{1}\right) y^{*}\right) \\
y^{*}=Q_{C}\left(x^{*}-\rho_{2}\left(\Psi_{2}+\Phi_{2}\right) x^{*}\right)
\end{array}\right.
$$

This proof is complete.

\section{Main results}

Let $C$ be a nonempty closed and convex subset of a real 2-uniformly smooth and uniformly convex Banach space $X$. Let $Q_{C}$ be a sunny nonexpansive retraction from $X$ onto $C$. Let $F: C \rightarrow X$ be a $\kappa$-Lipschitizian and $\eta$-strongly accretive operator with constants $\kappa, \eta>0, V: C \rightarrow C$ be an $L$-Lipschitzian mapping with a constant $L \geq 0$ and $T: C \rightarrow C$ be a nonexpansive mapping with $\operatorname{Fix}(T)=\varnothing$. Let $0<\mu<\frac{\eta}{\kappa^{2} K^{2}}$ and $0 \leq \gamma L<\tau$, where 
$\tau=\mu\left(\eta-\mu \kappa^{2} K^{2}\right)$. For each $t \in\left(0, \min \left\{1, \frac{1}{2 \tau}\right\}\right)$, consider the mapping $S_{t}: C \rightarrow C$ defined by

$$
S_{t} x=Q_{C}[t \gamma V x+(I-t \mu F) T x], \quad \forall x \in C .
$$

It is easy to see that $S_{t}$ is contractive. Indeed, from Lemma 2.17, for all $x, y \in C$, we have

$$
\begin{aligned}
\left\|S_{t} x-S_{t} y\right\| & =\left\|Q_{C}[t \gamma V x+(I-t \mu F) T x]-Q_{C}[t \gamma V y+(I-t \mu F) T y]\right\| \\
& \leq\|[t \gamma V x+(I-t \mu F) T x]-[t \gamma V y+(I-t \mu F) T \gamma]\| \\
& =\|t \gamma(V x-V y)+(I-t \mu F)(T x-T y)\| \\
& \leq t \gamma\|V x-V y\|+(1-t \tau)\|T x-T y\| \\
& \leq(1-(\tau-\gamma L) t)\|x-\gamma\| .
\end{aligned}
$$

Hence $S_{t}$ is contractive. By the Banach contraction principle, $S_{t}$ has a unique fixed point, denoted by $x_{t}$, which uniquely solves the fixed point equation

$$
x_{t}=Q_{C}\left[t \gamma V x_{t}+(I-t \mu F) T x_{t}\right] .
$$

Lemma 3.1. Let $C$ be a nonempty closed and convex subset of a real 2-uniformly smooth and uniformly convex Banach space $X$. Let $Q_{C}$ be a sunny nonexpansive retraction from $X$ onto $C$. Let $F: C \rightarrow X$ be a $\kappa$-Lipschitizian and $\eta$-strongly accretive operator with constants $\kappa, \eta>0, V: C \rightarrow C$ be an L-Lipschitzian mapping with a constant $L \geq 0$ and $T: C \rightarrow C$ be a nonexpansive mapping with $\operatorname{Fix}(T)=\varnothing$. Let $0<\mu<\frac{\eta}{\kappa^{2} K^{2}}$ and $0 \leq \gamma L<\tau$, where $\tau=\mu\left(\eta-\mu \kappa^{2} K^{2}\right)$. Then the net $\left\{x_{t}\right\}$ defined by (3.1) converges strongly to $\widehat{x} \in \operatorname{Fix}(T)$ as $t \rightarrow 0$, where $\widehat{x}$ is the unique solution of the variational inequality

$$
\langle(\mu F-\gamma V) \widehat{x}, j(\widehat{x}-v)\rangle \leq 0, \quad \forall v \in \operatorname{Fix}(T) .
$$

Proof. We observe that

$$
\begin{aligned}
\mu \kappa^{2} K^{2}>0 & \Leftrightarrow \eta-\mu \kappa^{2} K^{2}<\eta \\
& \Leftrightarrow \mu\left(\eta-\mu \kappa^{2} K^{2}\right)<\mu \eta \\
& \Leftrightarrow \tau<\mu \eta .
\end{aligned}
$$

It follows that

$$
0 \leq \gamma L<\tau<\mu \eta .
$$

First, we show the uniqueness of a solution of the variational inequality (3.2). Suppose that $\widehat{x}, \tilde{x} \in \operatorname{Fix}(T)$ are solution of (3.2), then

$$
\langle(\mu F-\gamma V) \widehat{x}, j(\widehat{x}-\tilde{x})\rangle \leq 0
$$

and

$$
\langle(\mu F-\gamma V) \widetilde{x}, j(\widetilde{x}-\widehat{x})\rangle \leq 0 .
$$


Adding up (3.4) and (3.5), we have

$$
\begin{aligned}
0 & \geq\langle(\mu F-\gamma V) \widehat{x}-(\mu F-\gamma V) \widetilde{x}, j(\widehat{x}-\widetilde{x})\rangle \\
& =\mu\langle F \widehat{x}-F \widetilde{x}, j(\widehat{x}-\widetilde{x})\rangle-\gamma\langle V \widehat{x}-V \widetilde{x}, j(\widehat{x}-\widetilde{x})\rangle \\
& \geq \mu \eta\left|\widehat{x}-\widetilde{x}\left\|^{2}-\gamma\right\| V \widehat{x}-V \widetilde{x}\right|\|\widehat{x}-\widetilde{x}\| \\
& \geq(\mu \eta-\gamma L)|| \widehat{x}-\widetilde{x} \|^{2} .
\end{aligned}
$$

Note that (3.3) implies that $\widehat{x}=\widetilde{x}$ and the uniqueness is proved. Below, we use $\widehat{x}$ to denote the unique solution of (3.2).

Next, we show that $\left\{x_{t}\right\}$ is bounded. Without loss of generality, we may assume that $t \leq \min \left\{1, \frac{1}{2 \tau}\right\}$. Take $p \in \operatorname{Fix}(T)$. From Lemma 2.17, we have

$$
\begin{aligned}
\left\|x_{t}-p\right\| & =\left\|Q_{C}\left[t \gamma V x_{t}+(I-t \mu F) T x_{t}\right]-Q_{C} p\right\| \\
& \leq\left\|t\left(\gamma V x_{t}-\mu F p\right)+(I-t \mu F)\left(T x_{t}-p\right)\right\| \\
& \leq t \gamma\left\|V x_{t}-V p\right\|+t\|\gamma V p-\mu F p\|+(1-t \tau)\left\|T x_{t}-p\right\| \\
& \leq(1-(\tau-\gamma L) t)\left\|x_{t}-p\right\|+t\|\gamma V p-\mu F p\| .
\end{aligned}
$$

It follows that

$$
\left\|x_{t}-p\right\| \leq \frac{\|\gamma \nabla p-\mu F p\|}{\tau-\gamma L} .
$$

Hence, $\left\{x_{t}\right\}$ is bounded, so are $\left\{V x_{t}\right\}$ and $\left\{F T x_{t}\right\}$. Assume $\left\{t_{n}\right\} \subset(0,1)$ is such that $t_{n} \rightarrow 0$ as $n \rightarrow \infty$. Set $x_{n}:=x_{t_{n}}$. Define a mapping $\varphi: C \rightarrow \mathbb{R}$ by

$$
\phi(x):=\operatorname{LIM}_{n}\left\|x_{n}-x\right\|^{2}, \quad \forall x \in C,
$$

where $L I M_{n}$ is a Banach limit on $l^{\infty}$. Note that $X$ is reflexive and $\varphi$ is continuous, convex functional and $\varphi(x) \rightarrow \infty$ as $\|x\| \rightarrow \infty$. From Lemma 2.12, there exists $z \in C$ such that $\varphi(z)=\inf _{x \in \mathrm{C}} \varphi(x)$. This implies that the set

$$
K:=\left\{z \in C: \phi(z)=\inf _{x \in C} \phi(x)\right\} \neq \emptyset .
$$

Observe that

$$
\begin{aligned}
\left\|x_{n}-T x_{n}\right\| & =\left\|Q_{C}\left[t_{n} \gamma V x_{n}+\left(I-t_{n} \mu F\right) T x_{n}\right]-Q_{C} T x_{n}\right\| \\
& \leq t_{n}\left\|\gamma V x_{n}-\mu F T x_{n}\right\| \rightarrow 0 \text { as } n \rightarrow \infty .
\end{aligned}
$$

For all $z \in C$, we have

$$
\begin{aligned}
\phi(T z) & =\operatorname{LIM}_{n}\left\|x_{n}-T z\right\|^{2} \\
& =\operatorname{LIM}_{n}\left\|T x_{n}-T z\right\|^{2} \\
& \leq \operatorname{LIM}_{n}\left\|x_{n}-z\right\|^{2} \\
& =\phi(z),
\end{aligned}
$$

which implies that $T(K) \subset K$; that is, $K$ is invariant under $T$. Since $X$ is a uniformly smooth Banach space, it has the fixed point property for nonexpansive mapping $T$. Then, there exists $\widetilde{x} \in K$ such that $T \widetilde{x}=\widetilde{x}$. Since $\widetilde{x}$ is also minimization of $\varphi$ over $C$, it follows that $x \in C$ and $t \in(0,1)$,

$$
\phi(\widetilde{x}) \leq \phi(\widetilde{x}+t(x-\mu F \widetilde{x})) .
$$


From Lemma 2.9, we have

$$
\left\|x_{n}-\tilde{x}+t(\mu F \tilde{x}-x)\right\|^{2} \leq\left\|x_{n}-\tilde{x}\right\|^{2}+2 t\left\langle\mu F \tilde{x}-x, j\left(x_{n}-\tilde{x}+t(\mu F \tilde{x}-x)\right)\right\rangle .
$$

Taking Banach limit over $n \geq 1$, then

$$
\operatorname{LIM}_{n}\left\|x_{n}-\tilde{x}+t(\mu F \tilde{x}-x)\right\|^{2} \leq \operatorname{LIM}_{n}\left\|x_{n}-\tilde{x}\right\|^{2}+2 t \operatorname{LIM}_{n}\left\langle\mu F \tilde{x}-x, j\left(x_{n}-\tilde{x}+t(\mu F \tilde{x}-x)\right)\right\rangle,
$$

which in turn implies that

$$
\begin{aligned}
2 t \operatorname{LIM}_{n}\left\langle x-\mu F \tilde{x}, j\left(x_{n}-\tilde{x}+t(\mu F \tilde{x}-x)\right)\right\rangle & \leq \operatorname{LIM}_{n}\left\|x_{n}-\tilde{x}\right\|^{2}-\operatorname{LIM}_{n}\left\|x_{n}-\tilde{x}+t(\mu F \tilde{x}-x)\right\|^{2} \\
& \leq 0
\end{aligned}
$$

and hence

$$
\operatorname{LIM}_{n}\left\langle x-\mu \widetilde{F}, j\left(x_{n}-\widetilde{x}+t(\mu F \widetilde{x}-x)\right)\right\rangle \leq 0
$$

Again since $X$ is a uniformly smooth Banach space, we have that the duality mapping $j$ is norm-to-norm uniformly continuous on a bounded subset of $C$ (see [9], Lemma 1), letting $t \rightarrow 0$, we obtain

$$
\operatorname{LIM}_{n}\left\langle x-\mu F \tilde{x}, j\left(x_{n}-\tilde{x}\right)\right\rangle \leq 0, \quad \forall x \in C .
$$

In particular

$$
\operatorname{LIM}_{n}\left\langle\gamma \sqrt{x}-\mu \widetilde{F}, j\left(x_{n}-\tilde{x}\right)\right\rangle \leq 0 .
$$

Set $x_{t}=Q_{C} y_{t}$, where $y_{t}=t \gamma V x_{t}+(I-t \mu F) T x_{t}$. Notice that $x_{n}:=x_{t_{n}}$ and $y_{n}:=y_{t_{n}}$. For $\tilde{x} \in \operatorname{Fix}(T)$, by Lemma 2.6(c), we have

$$
\begin{aligned}
\left\|x_{n}-\tilde{x}\right\|^{2} & =\left\langle y_{n}-\tilde{x}, j\left(x_{n}-\tilde{x}\right)\right\rangle+\left\langle Q_{C} y_{n}-y_{n}, j\left(Q_{C} y_{n}-\tilde{x}\right)\right\rangle \\
& \leq\left\langle y_{n}-\tilde{x}, j\left(x_{n}-\tilde{x}\right)\right\rangle \\
& =t_{n}\left\langle\gamma V x_{n}-\mu F \widetilde{x}, j\left(x_{n}-\widetilde{x}\right)\right\rangle+\left\langle\left(I-t_{n} \mu F\right)\left(T x_{n}-\widetilde{x}\right), j\left(x_{n}-\tilde{x}\right)\right\rangle \\
& \leq t_{n}\left\langle\gamma V x_{n}-\mu F \tilde{x}, j\left(x_{n}-\tilde{x}\right)\right\rangle+\left(1-t_{n} \tau\right)\left\|x_{n}-\tilde{x}\right\|^{2} .
\end{aligned}
$$

Thus, we have

$$
\begin{aligned}
\left\|x_{n}-\tilde{x}\right\|^{2} & \leq \frac{1}{\tau}\left\langle\gamma V x_{n}-\mu F \widetilde{x}, j\left(x_{n}-\widetilde{x}\right)\right\rangle \\
& =\frac{1}{\tau}\left\{\gamma\left\langle V x_{n}-V \widetilde{x}, j\left(x_{n}-\widetilde{x}\right)\right\rangle+\left\langle\gamma V \widetilde{x}-\mu F \widetilde{x}, j\left(x_{n}-\widetilde{x}\right)\right\rangle\right\} \\
& \leq \frac{1}{\tau}\left\{\gamma L\left\|x_{n}-\widetilde{x}\right\|^{2}+\left\langle\gamma V \widetilde{x}-\mu F \widetilde{x}, j\left(x_{n}-\tilde{x}\right)\right\rangle\right\}
\end{aligned}
$$

which implies that

$$
\left\|x_{n}-\tilde{x}\right\|^{2} \leq \frac{1}{\tau-\gamma L}\left\langle\gamma V \widetilde{x}-\mu F \widetilde{x}, j\left(x_{n}-\tilde{x}\right)\right\rangle .
$$

It follows from (3.7) that

$$
\operatorname{LIM}_{n}\left\|x_{n}-\tilde{x}\right\|^{2} \leq \frac{1}{\tau-\gamma L} \operatorname{LIM}_{n}\left\langle\gamma \sqrt{x}-\mu F \tilde{x}, j\left(x_{n}-\tilde{x}\right)\right\rangle \leq 0 .
$$

This implies that $\operatorname{LIM}_{n}|| x_{n}-\widetilde{x} \|=0$. Hence, there exists a subsequence $\left\{x_{n_{i}}\right\}$ of $\left\{x_{n}\right\}$ such that $x_{n_{i}} \rightarrow \tilde{x}$ as $i \rightarrow \infty$. From (3.6) and Lemma 2.14, we get $\tilde{x} \in \operatorname{Fix}(T)$. 
Next, we show that $\widetilde{x}$ solves the variational inequality (3.2). We note that

$$
x_{t}=Q_{C} y_{t}=Q_{C} y_{t}-y_{t}+t \gamma V x_{t}+(I-t \mu F) T x_{t},
$$

which derives that

$$
(\mu F-\gamma V) x_{t}=\frac{1}{t}\left(Q_{C} y_{t}-y_{t}\right)-\frac{1}{t}(I-T) x_{t}+\mu\left(F x_{t}-F T x_{t}\right) .
$$

Note that $I-T$ is accretive (i.e., $\langle(I-T) x-(I-T) y, j(x-y)\rangle \geq 0$, for $x, y \in C$ ). For all $v \in \operatorname{Fix}(T)$, it follows from (3.9) and Lemma 2.6(c) that

$$
\begin{aligned}
\left\langle(\mu F-\gamma V) x_{t}, j\left(x_{t}-v\right)\right\rangle= & \frac{1}{t}\left\langle Q_{C} y_{t}-y_{t}, j\left(Q_{C} y_{t}-v\right)\right\rangle-\frac{1}{t}\left\langle(I-T) x_{t}-(I-T) v, j\left(x_{t}-v\right)\right\rangle \\
& +\mu\left\langle F x_{t}-F T x_{t}, j\left(x_{t}-v\right)\right\rangle \\
\leq & \mu\left\langle F x_{t}-F T x_{t}, j\left(x_{t}-v\right)\right\rangle \\
\leq & \leq \mu\left\|F x_{t}-F T x_{t}\right\|\left\|x_{t}-v\right\| \\
\leq & \left\|x_{t}-T x_{t}\right\| M
\end{aligned}
$$

where $M=\sup _{n} \geq 1\left\{\mu \kappa|| x_{t}-v \|\right\}$ and $t \in\left(0, \min \left\{1, \frac{1}{2 \tau}\right\}\right)$. Now, replacing $t$ in (3.10) with $t_{n}$ and taking the limit as $n \rightarrow \infty$, we noticing that $x_{t_{n}}-T x_{t_{n}} \rightarrow \tilde{x} \rightarrow T \widetilde{x}=0$ for $\tilde{x} \in \operatorname{Fix}(T)$, we obtain $\langle(\mu F-\gamma V) \widetilde{x}, j(\widetilde{x}-v)\rangle \leq 0$. Hence $\tilde{x} \in \operatorname{Fix}(T)$ is the solution of the variational inequality (3.2). Consequently, $\widehat{x}=\tilde{x}$ by uniqueness. Therefore, $x_{t} \rightarrow \widehat{x}$ as $t \rightarrow 0$. This completes the proof.

Lemma 3.2. Let $C$ be a nonempty closed and convex subset of a real 2-uniformly smooth and uniformly convex Banach space $X$. Let $Q_{C}$ be a sunny nonexpansive retraction from $X$ onto $C$. Let $F: C \rightarrow X$ be a $\kappa$-Lipschitizian and $\eta$-strongly accretive operator with constants $\kappa, \eta>0, V: C \rightarrow C$ be an L-Lipschitzian mapping with a constant $L \geq 0$ and $T: C \rightarrow C$ be a nonexpansive mapping with $\operatorname{Fix}(T)=\varnothing$. Let $0<\mu<\frac{\eta}{\kappa^{2} K^{2}}$ and $0 \leq \gamma L<\tau$, where $\tau=\mu\left(\eta-\mu \kappa^{2} K^{2}\right)$. Assume that the net $\left\{x_{t}\right\}$ defined by (3.1) converges strongly to $\widehat{x} \in \operatorname{Fix}(T)$ as $t \rightarrow 0$. Suppose that $\left\{x_{n}\right\}$ is bounded and $\lim _{n \rightarrow \infty} \| x_{n}$ $-T x_{n}||=0$. Then

$$
\lim \sup _{n \rightarrow \infty}\left\langle\gamma \sqrt{x}-\mu F \widehat{x}, j\left(x_{n}-\widehat{x}\right)\right\rangle \leq 0 .
$$

Proof. Notice that $x_{t}=Q_{C} y_{t}$, where $y_{t}=t \gamma V x_{t}+(I-t \mu F) T x_{t}$. We note that

$$
\begin{aligned}
y_{t}-x_{n} & =t \gamma V x_{t}+(I-t \mu F) T x_{t}-x_{n} \\
& =t\left(\gamma V x_{t}-\mu F x_{t}\right)+T x_{t}-x_{n}+t \mu\left(F x_{t}-F T x_{t}\right) \\
& =t\left(\gamma V x_{t}-\mu F x_{t}\right)+\left(T x_{t}-T x_{n}\right)+\left(T x_{n}-x_{n}\right)+t \mu\left(F Q_{C} y_{t}-F Q_{C} T x_{t}\right) .
\end{aligned}
$$

It follows from Lemma 2.6(c) that

$$
\begin{aligned}
\left\|x_{t}-x_{n}\right\|^{2}= & \left\langle y_{t}-x_{n}, j\left(x_{t}-x_{n}\right)\right\rangle+\left\langle Q_{C} y_{t}-y_{t}, j\left(Q_{C} y_{t}-x_{n}\right)\right\rangle \\
\leq & \left\langle y_{t}-x_{n}, j\left(x_{t}-x_{n}\right)\right\rangle \\
= & t\left\langle\gamma V x_{t}-\mu F x_{t}, j\left(x_{t}-x_{n}\right)\right\rangle+\left\langle T x_{t}-T x_{n}, j\left(x_{t}-x_{n}\right)\right\rangle+\left\langle T x_{n}-x_{n}, j\left(x_{t}-x_{n}\right)\right\rangle \\
& +t \mu\left\langle F Q_{C} y_{t}-F Q_{C} T x_{t}, j\left(x_{t}-x_{n}\right)\right\rangle \\
\leq & t\left\langle\gamma V x_{t}-\mu F x_{t}, j\left(x_{t}-x_{n}\right)\right\rangle+\left\|x_{t}-x_{n}\right\|^{2}+\left\|T x_{n}-x_{n}\right\|\left\|x_{t}-x_{n}\right\| \\
& +t \mu \kappa\left\|Q_{C} y_{t}-Q_{C} T x_{t}\right\|\left\|x_{t}-x_{n}\right\| \\
\leq & t\left\langle\gamma V x_{t}-\mu F x_{t}, j\left(x_{t}-x_{n}\right)\right\rangle+\left\|x_{t}-x_{n}\right\|^{2}+\left\|T x_{n}-x_{n}\right\|\left\|x_{t}-x_{n}\right\| \\
& +t^{2} \mu \kappa\left\|\gamma V x_{t}-\mu F T x_{t}\right\|\left\|x_{t}-x_{n}\right\|,
\end{aligned}
$$


which in turn implies that

$$
\left\langle\gamma V x_{t}-\mu F x_{t}, j\left(x_{n}-x_{t}\right)\right\rangle \leq \frac{\left\|T x_{n}-x_{n}\right\|}{t}\left\|x_{t}-x_{n}\right\|+t \mu \kappa\left\|\gamma V x_{t}-\mu F T x_{t}\right\| .
$$

Since $x_{n}-T x_{n} \rightarrow 0$ as $n \rightarrow \infty$, taking the upper limit as $n \rightarrow \infty$ firstly, and then as $t$ $\rightarrow 0$ in (3.12), we have

$$
\limsup _{t \rightarrow 0} \limsup \sup _{n \rightarrow \infty}\left\langle\gamma V x_{t}-\mu F x_{t}, j\left(x_{n}-x_{t}\right)\right\rangle \leq 0 .
$$

On the other hand, we note that

$$
\begin{aligned}
\left\langle\gamma V \hat{x}-\mu F \widehat{x}, j\left(x_{n}-\widehat{x}\right)\right\rangle= & \left\langle\gamma V \widehat{x}-\mu F \widehat{x}, j\left(x_{n}-\widehat{x}\right)\right\rangle-\left\langle\gamma V \widehat{x}-\mu F \widehat{x}, j\left(x_{n}-x_{t}\right)\right\rangle \\
& +\left\langle\gamma V \widehat{x}-\mu F \widehat{x}, j\left(x_{n}-x_{t}\right)\right\rangle-\left\langle\gamma V \widehat{x}-\mu F x_{t}, j\left(x_{n}-x_{t}\right)\right\rangle \\
& +\left\langle\gamma V \widehat{x}-\mu F x_{t}, j\left(x_{n}-x_{t}\right)\right\rangle-\left\langle\gamma V x_{t}-\mu F x_{t}, j\left(x_{n}-x_{t}\right)\right\rangle \\
& +\left\langle\gamma V x_{t}-\mu F x_{t}, j\left(x_{n}-x_{t}\right)\right\rangle \\
= & \left\langle\gamma V \widehat{x}-\mu F \widehat{x}, j\left(x_{n}-\widehat{x}\right)-j\left(x_{n}-x_{t}\right)\right\rangle+\mu\left\langle F x_{t}-F \widehat{x}, j\left(x_{n}-x_{t}\right)\right\rangle \\
& +\gamma\left\langle V \widehat{x}-V x_{t}, j\left(x_{n}-x_{t}\right)\right\rangle+\left\langle\gamma V x_{t}-\mu F x_{t}, j\left(x_{n}-x_{t}\right)\right\rangle .
\end{aligned}
$$

Taking the upper limit as $n \rightarrow \infty$, we have

$$
\begin{aligned}
\limsup _{n \rightarrow \infty}\left\langle\gamma V \widehat{x}-\mu F \widehat{x}, j\left(x_{n}-\widehat{x}\right)\right\rangle \leq & \limsup _{n \rightarrow \infty}\left\langle\gamma V \widehat{x}-\mu F \widehat{x}, j\left(x_{n}-\widehat{x}\right)-j\left(x_{n}-x_{t}\right)\right\rangle \\
& +(\mu \kappa+\gamma L)|| x_{t}-\widehat{x}\left\|\lim \sup _{n \rightarrow \infty}|| x_{n}-x_{t}\right\| \\
& +\lim \sup _{n \rightarrow \infty}\left\langle\gamma V x_{t}-\mu F x_{t}, j\left(x_{n}-x_{t}\right)\right\rangle .
\end{aligned}
$$

Since $X$ is a uniformly smooth Banach space, we have that the duality mapping $j$ is norm-to-norm uniformly continuous on bounded subset of $C$ (see [9], Lemma 1), then

$$
\limsup _{t \rightarrow 0} \limsup \sup _{n \rightarrow \infty}\left\langle\gamma V \widehat{x}-\mu F \widehat{x}, j\left(x_{n}-\widehat{x}\right)-j\left(x_{n}-x_{t}\right)\right\rangle=0 .
$$

Then, from (3.13) and (3.14), we have

$$
\begin{aligned}
\lim \sup _{n \rightarrow \infty}\left\langle\gamma V \widehat{x}-\mu F \widehat{x}, j\left(x_{n}-\widehat{x}\right)\right\rangle & =\limsup \sup _{t \rightarrow 0} \lim \sup _{n \rightarrow \infty}\left\langle\gamma V \widehat{x}-\mu F \widehat{x}, j\left(x_{n}-\widehat{x}\right)\right\rangle \\
& \leq \lim \sup _{t \rightarrow 0} \lim \sup _{n \rightarrow \infty}\left\langle\gamma V x_{t}-\mu F x_{t}, j\left(x_{n}-x_{t}\right)\right\rangle \\
& \leq 0 .
\end{aligned}
$$

This completes the proof.

Theorem 3.3. Let $C$ be a nonempty closed and convex subset of a real 2-uniformly smooth and uniformly convex Banach space $X$. Let $Q_{C}$ be a sunny nonexpansive retraction from $X$ onto $C$. Let $F: C \rightarrow X$ be a $\kappa$-Lipschitizian and $\eta$-strongly accretive operator with constants $\kappa, \eta>0, V: C \rightarrow C$ be an L-Lipschitzian mapping with a constant $L \geq 0$. Let $0<\mu<\frac{\eta}{\kappa^{2} K^{2}}$ and $0 \leq \gamma L<\tau$, where $\tau=\mu\left(\eta-\mu \kappa{ }^{2} K^{2}\right)$. Let $\mathcal{S}=\{T(h): h>0\}$ be a u.a.r. nonexpansive semigroup from $C$ into itself such that $\operatorname{Fix}(\mathcal{S}):=\bigcap_{h>0} \operatorname{Fix}(T(h)) \neq \emptyset$ and least there exists a $T(h)$ which is demicompact. Let $\Psi_{i}: C \rightarrow X(i=1,2)$ be $\widetilde{\beta}_{i}$-inverse-strongly accretive and $\Phi_{i}: C \rightarrow X(i=1,2)$ be $\tilde{\gamma}_{i}$ -inverse-strongly accretive. Assume that $\Omega$ : $=\operatorname{Fix}(\mathcal{S}) \cap \operatorname{Fix}(G) \neq \emptyset$, where $G$ is defined as in Lemma 2.19. For given $x_{1} \in C$, let $\left\{x_{n}\right\}$ be a sequence defined by

$$
\left\{\begin{array}{l}
z_{n}=Q_{C}\left(x_{n}-\rho_{2}\left(\Psi_{2}+\Phi_{2}\right) x_{n}\right), \\
y_{n}=Q_{C}\left(z_{n}-\rho_{1}\left(\Psi_{1}+\Phi_{1}\right) z_{n}\right), \\
x_{n+1}=\beta_{n} x_{n}+\left(1-\beta_{n}\right) Q_{C}\left[\alpha_{n} \gamma V x_{n}+\left(I-\alpha_{n} \mu F\right) T\left(t_{n}\right) y_{n}\right], \quad \forall n \geq 1,
\end{array}\right.
$$


where $\rho_{i} \in\left(0, \min \left\{\frac{\widetilde{\beta}_{i}}{2 K^{2}}, \frac{\widetilde{\gamma}_{i}}{2 K^{2}}\right\}\right)$ for all $i=1$, 2. Suppose that $\left\{\alpha_{n}\right\}$ and $\left\{\beta_{n}\right\}$ are sequences in $[0,1]$ and $\left\{t_{n}\right\}$ is a sequence in $(0, \infty)$ satisfying the following conditions:

(C1) $\lim _{n \rightarrow \infty} \alpha_{n}=0$ and $\sum_{n=1}^{\infty} \alpha_{n}=\infty$;

(C2) $0<\lim \inf _{n \rightarrow \infty} \beta_{n} \leq \lim \sup _{n \rightarrow \infty} \beta_{n}<1$;

(C3) $t_{n+1}=h+t_{n}$ for all $h>0$ and $\lim _{n \rightarrow \infty} t_{n}=\infty$.

Then, the sequence $\left\{x_{n}\right\}$ defined by (3.15) converges strongly to $\widehat{x} \in \Omega$ as $n \rightarrow \infty$, which $\tilde{x}$ is the unique solution of the variational inequality

$$
\langle(\mu F-\gamma V) \tilde{x}, j(\widetilde{x}-v)\rangle \leq 0, \quad \forall v \in \Omega,
$$

and $(\widehat{x}, \widehat{y})$ is the solution of the problem (1.15), where $\hat{y}=Q_{C}\left(\widehat{x}-\rho_{2}\left(\Psi_{2}+\Phi_{2}\right) \widehat{x}\right)$.

Proof. Note that from the condition (C1), we assume without loss generality, that $\alpha_{n} \leq \min \left\{1, \frac{1}{2 \tau}\right\}$ for all $n \geq 1$. First, we show that $\left\{x_{n}\right\}$ is bounded. Take $x^{*} \in \Omega$. It follows from Lemma 2.19 that

$$
x^{*}=Q_{C}\left[Q_{C}\left(x-\rho_{2}\left(\Psi_{2}+\Phi_{2}\right) x^{*}\right)-\rho_{1}\left(\Psi_{1}+\Phi_{1}\right) Q_{C}\left(x^{*}-\rho_{2}\left(\Psi_{2}+\Phi_{2}\right) x^{*}\right)\right] .
$$

Put $y^{*}=Q_{C}\left(x^{*}-\rho_{2}\left(\Psi_{2}+\Phi_{2}\right) x^{*}\right)$, then $x^{*}=Q_{C}\left(y^{*}-\rho_{1}\left(\Psi_{1}+\Phi_{1}\right) y^{*}\right)$. From (3.15), we observe that

$$
\begin{aligned}
\left\|y_{n}-x^{*}\right\| & =\left\|G x_{n}-G x^{*}\right\| \\
& \leq\left\|x_{n}-x^{*}\right\| .
\end{aligned}
$$

Set $u_{n}=Q_{C}\left[\alpha_{n} \gamma V x_{n}+\left(I-\alpha_{n} \mu F\right) T\left(t_{n}\right) y_{n}\right]$. From Lemma 2.17, we have

$$
\begin{aligned}
\left\|u_{n}-x^{*}\right\| & =\left\|Q_{C}\left[\alpha_{n} \gamma V x_{n}+\left(I-\alpha_{n} \mu F\right) T\left(t_{n}\right) y_{n}\right]-Q_{C} x^{*}\right\| \\
& \leq\left\|\alpha_{n}\left(\gamma V x_{n}-\mu F x^{*}\right)+\left(I-\alpha_{n} \mu F\right)\left(T\left(t_{n}\right) y_{n}-x^{*}\right)\right\| \\
& \leq \alpha_{n} \gamma\left\|V x_{n}-V x^{*}\right\|+\alpha_{n}\left\|\gamma V x^{*}-\mu F x^{*}\right\|+\left(1-\alpha_{n} \tau\right)\left\|y_{n}-x^{*}\right\| \\
& \leq\left(1-(\tau-\gamma L) \alpha_{n}\right)\left\|x_{n}-x^{*}\right\|+\alpha_{n}\left\|\gamma V x^{*}-\mu F x^{*}\right\| .
\end{aligned}
$$

It follows that

$$
\begin{aligned}
\left\|x_{n+1}-x^{*}\right\| & =\left\|\beta_{n}\left(x_{n}-x^{*}\right)+\left(1-\beta_{n}\right)\left(u_{n}-x^{*}\right)\right\| \\
& \leq \beta_{n}\left\|x_{n}-x^{*}\right\|+\left(1-\beta_{n}\right)\left\|u_{n}-x^{*}\right\| \\
& \leq \beta_{n}\left\|x_{n}-x^{*}\right\|+\left(1-\beta_{n}\right)\left[\left(1-(\tau-\gamma L) \alpha_{n}\right)\left\|x_{n}-x^{*}\right\|+\alpha_{n}\left\|\gamma V x^{*}-\mu F x^{*}\right\|\right] \\
& =\left(1-(\tau-\gamma L) \alpha_{n}\left(1-\beta_{n}\right)\right)\left\|x_{n}-x^{*}\right\|+\alpha_{n}\left(1-\beta_{n}\right)(\tau-\gamma L) \frac{\left\|\gamma V x^{*}-\mu F x^{*}\right\|}{\tau-\gamma L} .
\end{aligned}
$$

By induction, we have

$$
\left\|x_{n}-x^{*}\right\| \leq \max \left\{\left\|x_{1}-x^{*}\right\|, \frac{\left\|\gamma V x^{*}-\mu F x^{*}\right\|}{\tau-\gamma L}\right\}, \quad \forall n \geq 1 .
$$

Hence, $\left\{x_{n}\right\}$ is bounded, so are $\left\{z_{n}\right\},\left\{y_{n}\right\}$ and $\left\{u_{n}\right\}$.

Next, we show that $\left\|x_{n+1}-x_{n}\right\| \rightarrow 0$ as $n \rightarrow \infty$. We observe that

$$
\begin{aligned}
\left\|y_{n+1}-y_{n}\right\| & =\left\|G x_{n+1}-G x_{n}\right\| \\
& \leq\left\|x_{n+1}-x^{*}\right\| .
\end{aligned}
$$

Now, we can take a constant $M>0$ such that

$$
M=\sup _{n \geq 1}\left\{\gamma\left\|V x_{n+1}\right\|+\mu|| F T\left(t_{n+1}\right) y_{n+1}\|, \gamma\| V x_{n}\|+\mu\| F T\left(t_{n}\right) y_{n} \|\right\} .
$$


Then, we have

$$
\begin{aligned}
\left\|u_{n+1}-u_{n}\right\| & =\left\|Q_{C}\left[\alpha_{n+1} \gamma V x_{n+1}+\left(I-\alpha_{n+1} \mu F\right) T\left(t_{n+1}\right) y_{n+1}\right]-Q_{C}\left[\alpha_{n} \gamma V x_{n}+\left(I-\alpha_{n} \mu F\right) T\left(t_{n}\right) y_{n}\right]\right\| \\
& \leq\left\|\alpha_{n+1} \gamma V x_{n+1}+\left(I-\alpha_{n+1} \mu F\right) T\left(t_{n+1}\right) y_{n+1}-\alpha_{n} \gamma V x_{n}-\left(I-\alpha_{n} \mu F\right) T\left(t_{n}\right) y_{n}\right\| \\
& \leq \alpha_{n+1}\left\|\gamma V x_{n+1}-\mu F T\left(t_{n+1}\right) y_{n+1}\right\|+\alpha_{n}\left\|\gamma V x_{n}-\mu F T\left(t_{n}\right) y_{n}\right\|+\left\|T\left(t_{n+1}\right) y_{n+1}-T\left(t_{n}\right) y_{n}\right\| \\
& \leq\left(\alpha_{n+1}+\alpha_{n}\right) M+\left\|y_{n+1}-y_{n}\right\|+\left\|T(h) T\left(t_{n}\right) y_{n}-T\left(t_{n}\right) y_{n}\right\| .
\end{aligned}
$$

Combining (3.17) and (3.18), we obtain

$$
\left\|u_{n+1}-u_{n}\right\|-\left\|x_{n+1}-x_{n}\right\| \leq\left(\alpha_{n+1}+\alpha_{n}\right) M+\left\|T(h) T\left(t_{n}\right) y_{n}-T\left(t_{n}\right) y_{n}\right\| .
$$

Since $\{T(h): h>0\}$ is a u.a.r. nonexpansive semigroup and $\lim _{n \rightarrow \infty} t_{n}=\infty$, then for all $h>0$, and for any bounded subset $B$ of $C$ containing $\left\{x_{n}\right\}$ and $\left\{y_{n}\right\}$, we obtain that

$$
\lim _{n \rightarrow \infty}\left\|T(h) T\left(t_{n}\right) y_{n}-T\left(t_{n}\right) y_{n}\right\| \leq \lim _{n \rightarrow \infty} \sup _{\omega \in B} \| T(h) T\left(t_{n}\right) \omega-T\left(t_{n}\right) \omega=0 .
$$

Consequently, it follows from the conditions $(C 1),(C 2)$ and (3.19) that

$$
\limsup _{n \rightarrow \infty}\left(\left\|u_{n+1}-u_{n}\right\|-\left\|x_{n+1}-x_{n}\right\|\right) \leq 0 .
$$

Hence, by Lemma 2.10 , we obtain that

$$
\lim _{n \rightarrow \infty}\left\|u_{n}-x_{n}\right\|=0 .
$$

Consequently, we have

$$
\lim _{n \rightarrow \infty}\left\|x_{n+1}-x_{n}\right\|=\lim _{n \rightarrow \infty}\left(1-\beta_{n}\right)\left\|u_{n}-x_{n}\right\|=0 .
$$

We observe that

$$
\begin{aligned}
\left\|u_{n}-T\left(t_{n}\right) y_{n}\right\| & =\left\|Q_{C}\left[\alpha_{n} \gamma f\left(x_{n}\right)+\left(I-\alpha_{n} \mu F\right) T\left(t_{n}\right) y_{n}\right]-Q_{C} T\left(t_{n}\right) y_{n}\right\| \\
& \leq \alpha_{n}\left\|\gamma f\left(x_{n}\right)-\mu F T\left(t_{n}\right) y_{n}\right\| \rightarrow 0 \text { as } n \rightarrow \infty .
\end{aligned}
$$

From (3.21) and (3.23), we have

$$
\left\|x_{n}-T\left(t_{n}\right) y_{n}\right\| \leq\left\|x_{n}-u_{n}\right\|+\left\|u_{n}-T\left(t_{n}\right) y_{n}\right\| \rightarrow 0 \text { as } n \rightarrow \infty .
$$

Next, we show that $\lim _{n \rightarrow \infty}|| x_{n}-T(h) x_{n} \|=0, \forall h>0$. For all $x^{*}, y^{*} \in \Omega$, by the convexity of $\|\cdot\|^{2}$ and Lemma 2.8 , we have

$$
\begin{aligned}
\left\|z_{n}-\gamma^{*}\right\|^{2}= & \left\|Q_{C}\left(x_{n}-\rho_{2}\left(\Psi_{2}+\Phi_{2}\right) x_{n}\right)-Q_{C}\left(x^{*}-\rho_{2}\left(\Psi_{2}+\Phi_{2}\right) x^{*}\right)\right\|^{2} \\
\leq & \left\|\left(x_{n}-\rho_{2}\left(\Psi_{2}+\Phi_{2}\right) x_{n}\right)-\left(x^{*}-\rho_{2}\left(\Psi_{2}+\Phi_{2}\right) x^{*}\right)\right\|^{2} \\
= & \left\|x_{n}-x^{*}-\rho_{2}\left[\left(\Psi_{2}+\Phi_{2}\right) x_{n}-\left(\Psi_{2}+\Phi_{2}\right) x^{*}\right]\right\|^{2} \\
= & \left\|\frac{1}{2}\left[x_{n}-x^{*}-2 \rho_{2}\left(\Psi_{2} x_{n}-\Psi_{2} x^{*}\right)\right]+\frac{1}{2}\left[x_{n}-x^{*}-2 \rho_{2}\left(\Phi_{2} x_{n}-\Phi_{2} x^{*}\right)\right]\right\|^{2} \\
\leq & \frac{1}{2}\left\|x_{n}-x^{*}-2 \rho_{2}\left(\Psi_{2} x_{n}-\Psi_{2} x^{*}\right)\right\|^{2}+\frac{1}{2}\left\|x_{n}-x^{*}-2 \rho_{2}\left(\Phi_{2} x_{n}-\Phi_{2} x^{*}\right)\right\|^{2} \\
\leq & \frac{1}{2}\left(\left\|x_{n}-x^{*}\right\|^{2}-4 \rho_{2}\left(\Psi_{2} x_{n}-\Psi_{2} x^{*}, x_{n}-x^{*}\right\rangle+8 \rho_{2}^{2} K^{2}\left\|\Psi_{2} x_{n}-\Psi_{2} x^{*}\right\|^{2}\right) \\
& +\frac{1}{2}\left(\left\|x_{n}-x^{*}\right\|^{2}-4 \rho_{2}\left\langle\Phi_{2} x_{n}-\Phi_{2} x^{*}, x_{n}-x^{*}\right\rangle+8 \rho_{2}^{2} K^{2}\left\|\Phi_{2} x_{n}-\Phi_{2} x^{*}\right\|^{2}\right) \\
\leq & \frac{1}{2}\left(\left\|x_{n}-x^{*}\right\|^{2}-4 \rho_{2} \widetilde{\beta}_{2}\left\|\Psi_{2} x_{n}-\Psi_{2} x^{*}\right\|^{2}+8 \rho_{2}^{2} K^{2}\left\|\Psi_{2} x_{n}-\Psi_{2} x_{n} x^{*}\right\|^{2}\right) \\
& +\frac{1}{2}\left(\left\|x_{n}-x^{*}\right\|-4 \rho_{2} \widetilde{\gamma}_{2}\left\|\Phi_{2} x_{n}-\Phi_{2} x^{*}\right\|^{2}+8 \rho_{2}^{2} K^{2}\left\|\Phi_{2} x_{n}-\Phi_{2} x_{n} x^{*}\right\|^{2}\right) \\
= & \left\|x_{n}-x^{*}\right\|^{2}+4 \rho_{2} K^{2}\left(\rho_{2}-\frac{\widetilde{\beta}_{2}}{2 K^{2}}\right)\left\|\Psi_{2} x_{n}-\Psi_{2} x^{*}\right\|^{2}+4 \rho_{2} K^{2}\left(\rho_{2}-\frac{\gamma_{2}}{2 K^{2}}\right)\left\|\Phi_{2} x_{n}-\Phi_{2} x^{*}\right\|^{2} .
\end{aligned}
$$

In a similar way, we can get

$$
\left\|y_{n}-x^{*}\right\|^{2} \leq\left\|z_{n}-\gamma^{*}\right\|^{2}+4 \rho_{1} K^{2}\left(\rho_{1}-\frac{\widetilde{\beta}_{1}}{2 K^{2}}\right)\left\|\Psi_{1} z_{n}-\Psi_{1} \gamma^{*}\right\|^{2}+4 \rho_{1} K^{2}\left(\rho_{1}-\frac{\widetilde{\gamma}_{1}}{2 K^{2}}\right)\left\|\Phi_{1} z_{n}-\Phi_{1} y^{*}\right\|^{2} .
$$


Substituting (3.25) into (3.26), we have

$$
\begin{aligned}
\left\|y_{n}-x^{*}\right\|^{2} \leq & \left\|x_{n}-x^{*}\right\|^{2}+4 \rho_{2} K^{2}\left(\rho_{2}-\frac{\widetilde{\beta}_{2}}{2 K^{2}}\right)\left\|\Psi_{2} x_{n}-\Psi_{2} x^{*}\right\|^{2}+4 \rho_{2} K^{2}\left(\rho_{2}-\frac{\widetilde{\gamma}_{2}}{2 K^{2}}\right)\left\|\Phi_{2} x_{n}-\Phi_{2} x^{*}\right\|^{2} \\
& +4 \rho_{1} K^{2}\left(\rho_{1}-\frac{\widetilde{\beta}_{1}}{2 K^{2}}\right)\left\|\Psi_{1} z_{n}-\Psi_{1} \gamma^{*}\right\|^{2}+4 \rho_{1} K^{2}\left(\rho_{1}-\frac{\widetilde{\gamma}_{1}}{2 K^{2}}\right)\left\|\Phi_{1} z_{n}-\Phi_{1} \gamma^{*}\right\|^{2} .
\end{aligned}
$$

Set $u_{n}=Q_{C} v_{n}$, where $v_{n}=\alpha_{n} \gamma V x_{n}+\left(I-\alpha_{n} \mu F\right) T\left(t_{n}\right) y_{n}$. From Lemma 2.6(c), we have

$$
\begin{aligned}
\left\|u_{n}-x^{*}\right\|^{2} & =\left\langle v_{n}-x^{*}, j\left(u_{n}-x^{*}\right)\right\rangle+\left\langle Q_{C} v_{n}-v_{n}, j\left(Q_{C} v_{n}-x^{*}\right)\right\rangle \\
& \leq\left\langle v_{n}-x^{*}, j\left(u_{n}-x^{*}\right)\right\rangle \\
& =\alpha_{n}\left\langle\gamma V x_{n}-\mu F x^{*}, j\left(u_{n}-x^{*}\right)\right\rangle+\left\langle\left(I-\alpha_{n} \mu F\right)\left(T\left(t_{n}\right) y_{n}-x^{*}\right), j\left(u_{n}-x^{*}\right)\right\rangle \\
& \leq\left(1-\alpha_{n} \tau\right)\left\|y_{n}-x^{*}\right\|\left\|u_{n}-x^{*}\right\|+\alpha_{n}\left\langle\gamma V x_{n}-\mu F x^{*}, j\left(u_{n}-x^{*}\right)\right\rangle \\
& \leq \frac{\left(1-\alpha_{n} \tau\right)}{2}\left(\left\|y_{n}-x^{*}\right\|^{2}+\left\|u_{n}-x^{*}\right\|^{2}\right)+\alpha_{n}\left\langle\gamma V x_{n}-\mu F x^{*}, j\left(u_{n}-x^{*}\right)\right\rangle \\
& \leq \frac{\left(1-\alpha_{n} \tau\right)}{2}\left\|y_{n}-x^{*}\right\|^{2}+\frac{1}{2}\left\|u_{n}-x^{*}\right\|^{2}+\alpha_{n}\left\langle\gamma V x_{n}-\mu F x^{*}, j\left(u_{n}-x^{*}\right)\right\rangle .
\end{aligned}
$$

It follows that

$$
\begin{aligned}
\left\|u_{n}-x^{*}\right\|^{2} & \leq\left\|y_{n}-x^{*}\right\|^{2}+2 \alpha_{n}\left\langle\gamma V x_{n}-\mu F x^{*}, j\left(u_{n}-x^{*}\right)\right\rangle \\
& \leq\left\|y_{n}-x^{*}\right\|^{2}+2 \alpha_{n}\left\|\gamma V x_{n}-\mu F x^{*}\right\|\left\|u_{n}-x^{*}\right\| .
\end{aligned}
$$

By the convexity of $\|\cdot\|^{2}$ and (3.28), we have

$$
\begin{aligned}
\left\|x_{n+1}-x^{*}\right\|^{2} & =\left\|\beta_{n}\left(x_{n}-x^{*}\right)+\left(1-\beta_{n}\right)\left(u_{n}-x^{*}\right)\right\|^{2} \\
& \leq \beta_{n}\left\|x_{n}-x^{*}\right\|^{2}+\left(1-\beta_{n}\right)\left\|u_{n}-x_{n}\right\|^{2} \\
& \leq \beta_{n}\left\|x_{n}-x^{*}\right\|^{2}+\left(1-\beta_{n}\right)\left\{\left\|y_{n}-x^{*}\right\|^{2}+2 \alpha_{n}\left\|\gamma V x_{n}-\mu F x^{*}\right\|\left\|u_{n}-x^{*}\right\|\right\} \\
& =\beta_{n}\left\|x_{n}-x^{*}\right\|^{2}+\left(1-\beta_{n}\right)\left\|y_{n}-x^{*}\right\|^{2}+2 \alpha_{n}\left(1-\beta_{n}\right)\left\|\gamma V x_{n}-\mu F x^{*}\right\|\left\|u_{n}-x^{*}\right\| .
\end{aligned}
$$

Substituting (3.27) into (3.29), we have

$$
\begin{aligned}
\left\|x_{n+1}-x^{*}\right\|^{2} \leq & \beta_{n}\left\|x_{n}-x^{*}\right\|^{2}+\left(1-\beta_{n}\right)\left\{\left\|x_{n}-x^{*}\right\|^{2}+4 \rho_{2} K^{2}\left(\rho_{2}-\frac{\widetilde{\beta}_{2}}{2 K^{2}}\right)\left\|\Psi_{2} x_{n}-\Psi_{2} x^{*}\right\|^{2}\right. \\
& +4 \rho_{2} K^{2}\left(\rho_{2}-\frac{\widetilde{\gamma}_{2}}{2 K^{2}}\right)\left\|\Phi_{2} x_{n}-\Phi_{2} x^{*}\right\|^{2}+4 \rho_{1} K^{2}\left(\rho_{1}-\frac{\widetilde{\beta}_{1}}{2 K^{2}}\right)\left\|\Psi_{1} z_{n}-\Psi_{1} \gamma^{*}\right\|^{2} \\
& \left.\left.+4 \rho_{1} K^{2}\left(\rho_{1}-\frac{\widetilde{\gamma}_{2}}{2 K^{2}}\right)\left\|\Phi_{1} z_{n}-\Phi_{1} \gamma^{*}\right\|^{2}\right\}+2 \alpha_{n}\left(1-\beta_{n}\right)\left\|\gamma V x_{n}-\mu F x^{*}\right\|\left\|u_{n}-x^{*}\right\|\right\} \\
= & \left\|x_{n}-x^{*}\right\|^{2}+\left(1-\beta_{n}\right)\left\{4 \rho_{2} K^{2}\left(\rho_{2}-\frac{\widetilde{\beta}_{2}}{2 K^{2}}\right)\left\|\Psi_{2} x_{n}-\Psi_{2} x^{*}\right\|^{2}\right. \\
& +4 \rho_{2} K^{2}\left(\rho_{2}-\frac{\widetilde{\gamma}_{2}}{2 K^{2}}\right)\left\|\Phi_{2} x_{n}-\Phi_{2} x^{*}\right\|^{2} \\
& \left.4 \rho_{1} K^{2}\left(\rho_{1}-\frac{\widetilde{\beta}_{1}}{2 K^{2}}\right)\left\|\Psi_{1} z_{n}-\Psi_{1} y^{*}\right\|^{2}+4 \rho_{1} K^{2}\left(\rho_{1}-\frac{\widetilde{\gamma}_{1}}{2 K^{2}}\right)\left\|\Phi_{1} z_{n}-\Phi_{1} \gamma^{*}\right\|^{2}\right\} \\
& +2 \alpha_{n}\left(1-\beta_{n}\right)\left\|\gamma V x_{n}-\mu F x^{*}\right\|\left\|u_{n}-x^{*}\right\|,
\end{aligned}
$$

which in turn implies that

$$
\begin{aligned}
\left(1-\beta_{n}\right) & \left\{4 \rho_{2} K^{2}\left(\frac{\widetilde{\beta}_{2}}{2 K^{2}}-\rho_{2}\right)\left\|\Psi_{2} x_{n}-\Psi_{2} x^{*}\right\|^{2}+4 \rho_{2} K^{2}\left(\frac{\tilde{\gamma}_{2}}{2 K^{2}}-\rho_{2}\right)\left\|\Phi_{2} x_{n}-\Phi_{2} x^{*}\right\|^{2}\right. \\
+ & \left.4 \rho_{1} K^{2}\left(\frac{\widetilde{\beta}_{1}}{2 K^{2}}-\rho_{1}\right)\left\|\Psi_{1} z_{n}-\Psi_{1} \gamma^{*}\right\|^{2}+4 \rho_{1} K^{2}\left(\frac{\tilde{\gamma}_{1}}{2 K^{2}}-\rho_{1}\right)\left\|\Phi_{1} z_{n}-\Phi_{1} \gamma^{*}\right\|^{2}\right\} \\
& \leq\left\|x_{n}-x^{*}\right\|^{2}-\left\|x_{n+1}-x_{n}\right\|^{2}+2 \alpha_{n}\left(1-\beta_{n}\right)\left\|\gamma V x_{n}-\mu F x^{*}\right\|\left\|u_{n}-x^{*}\right\| \\
& \leq\left(\left\|x_{n}-x^{*}\right\|+\left\|x_{n+1}-x^{*}\right\|\right)\left\|x_{n+1}-x_{n}\right\|+2 \alpha_{n}\left(1-\beta_{n}\right)\left\|\gamma V x_{n}-\mu F x^{*}\right\|\left\|u_{n}-x^{*}\right\| .
\end{aligned}
$$


Since $\lim \inf _{n \rightarrow \infty}\left(1-\beta_{n}\right)>0,0<\rho_{i}<\min \left\{\frac{\widetilde{\beta}_{i}}{2 K^{2}}, \frac{\widetilde{\gamma}_{i}}{2 K^{2}}\right\}$, for all $i=1,2,\left\|x_{n+1}-x_{n}\right\| \rightarrow 0$ and $\alpha_{n} \rightarrow 0$, we have

$$
\left\{\begin{array}{l}
\lim _{n \rightarrow \infty}\left\|\Psi_{1} z_{n}-\Psi_{1} \gamma^{*}\right\|=\lim _{n \rightarrow \infty}\left\|\Phi_{1} z_{n}-\Phi_{1} y^{*}\right\|=0 \\
\lim _{n \rightarrow \infty}\left\|\Psi_{2} x_{n}-\Psi_{2} x^{*}\right\|=\lim _{n \rightarrow \infty}\left\|\Phi_{2} x_{n}-\Phi_{2} x^{*}\right\|=0 .
\end{array}\right.
$$

Let $r_{1}=\sup _{n} \geq 1\left\{\left\|z_{n}-y^{*}\right\|, \| y_{n}-x^{*}||\right\}$. By Lemma 2.6(b) and Lemma 2.15, we have

$$
\begin{aligned}
\left\|y_{n}-x^{*}\right\|^{2}= & \left\|Q_{C}\left(z_{n}-\rho_{1}\left(\Psi_{1}+\Phi_{1}\right) z_{n}\right)-Q_{C}\left(y^{*}-\rho_{1}\left(\Psi_{1}+\Phi_{1}\right) y^{*}\right)\right\|^{2} \\
\leq & \left\langle z_{n}-\rho_{1}\left(\Psi_{1}+\Phi_{1}\right) z_{n}-\left(y^{*}-\rho_{1}\left(\Psi_{1}+\Phi_{1}\right) y^{*}\right), j\left(y_{n}-x^{*}\right)\right\rangle \\
= & \left\langle z_{n}-\gamma^{*}, j\left(y_{n}-x^{*}\right)\right\rangle-\rho_{1}\left\langle\left(\Psi_{1}+\Phi_{1}\right) z_{n}-\left(\Psi_{1}+\Phi_{1}\right) y^{*}, j\left(y_{n}-x^{*}\right)\right\rangle \\
\leq & \frac{1}{2}\left\{\left\|z_{n}-y^{*}\right\|^{2}+\left\|y_{n}-x^{*}\right\|^{2}-g_{1}\left(\left\|z_{n}-y_{n}+x^{*}-y^{*}\right\|\right)\right\} \\
& -\rho_{1}\left\langle\left(\Psi_{1}+\Phi_{1}\right) z_{n}-\left(\Psi_{1}+\Phi_{1}\right) y^{*}, j\left(y_{n}-x^{*}\right)\right\rangle,
\end{aligned}
$$

which in turn implies that

$$
\begin{aligned}
\left\|y_{n}-x^{*}\right\|^{2} & \left.\leq\left\|z_{n}-\gamma^{*}\right\|^{2}-g_{1}\left(\| z_{n}-\gamma_{n}+x^{*}-\gamma^{*}\right) \|\right)-2 \rho_{1}\left\langle\left(\Psi_{1}+\Phi_{1}\right) z_{n}-\left(\Psi_{1}+\Phi_{1}\right) \gamma^{*}, j\left(y_{n}-x^{*}\right)\right\rangle \\
& \leq\left\|z_{n}-\gamma^{*}\right\|^{2}-g_{1}\left(\left\|z_{n}-\gamma_{n}+x^{*}-\gamma^{*}\right\|\right)+2 \rho_{1}\left\|\left(\Psi_{1}+\Phi_{1}\right) z_{n}-\left(\Psi_{1}+\Phi_{1}\right) \gamma^{*}\right\|\left\|y_{n}-x^{*}\right\| .
\end{aligned}
$$

Let $r_{2}=\sup _{n} \geq 1\left\{|| x_{n}-x^{*}\|,\| z_{n}-y^{*}||\right\}$. Again, by Lemma 2.6(b) and Lemma 2.15, we have

$$
\begin{aligned}
\left\|z_{n}-y^{*}\right\|^{2}= & \left\|Q_{C}\left(x_{n}-\rho_{2}\left(\Psi_{2}+\Phi_{2}\right) x_{n}\right)-Q_{C}\left(x^{*}-\rho_{2}\left(\Psi_{2}+\Phi_{2}\right) x^{*}\right)\right\|^{2} \\
\leq & \left\langle x_{n}-\rho_{2}\left(\Psi_{2}+\Phi_{2}\right) x_{n}-\left(x^{*}-\rho_{2}\left(\Psi_{2}+\Phi_{2}\right) x^{*}\right), j\left(z_{n}-y^{*}\right)\right\rangle \\
= & \left\langle x_{n}-x^{*}, j\left(z_{n}-y^{*}\right)\right\rangle-\rho_{2}\left\langle\left(\Psi_{2}+\Phi_{2}\right) x_{n}-\left(\Psi_{2}+\Phi_{2}\right) x^{*}, j\left(z_{n}-y^{*}\right)\right\rangle \\
\leq & \frac{1}{2}\left\{\left\|x_{n}-x^{*}\right\|^{2}+\left\|z_{n}-y^{*}\right\|^{2}-g_{2}\left(\left\|x_{n}-z_{n}-\left(x^{*}-y^{*}\right)\right\|\right)\right\} \\
& -\rho_{2}\left\langle\left(\Psi_{2}+\Phi_{2}\right) x_{n}-\left(\Psi_{2}+\Phi_{2}\right) x^{*}, j\left(z_{n}-\gamma^{*}\right)\right\rangle,
\end{aligned}
$$

which in turn implies that

$$
\begin{aligned}
\left\|z_{n}-\gamma^{*}\right\|^{2} & \leq\left\|x_{n}-x^{*}\right\|^{2}-g_{2}\left(\left\|x_{n}-z_{n}-\left(x^{*}-\gamma^{*}\right)\right\|\right)-2 \rho_{2}\left\langle\left(\Psi_{2}+\Phi_{2}\right) x_{n}-\left(\Psi_{2}+\Phi_{2}\right) x^{*}, j\left(z_{n}-\gamma^{*}\right)\right\rangle \\
& \leq\left\|x_{n}-x^{*}\right\|^{2}-g_{2}\left(\left\|x_{n}-z_{n}-\left(x^{*}-\gamma^{*}\right)\right\|\right)+2 \rho_{2}\left\|\left(\Psi_{2}+\Phi_{2}\right) x_{n}-\left(\Psi_{2}+\Phi_{2}\right) x^{*}\right\|\left\|z_{n}-\gamma^{*}\right\| .
\end{aligned}
$$

Substituting (3.32) into (3.31), we obtain

$$
\begin{aligned}
\left\|y_{n}-x^{*}\right\|^{2} \leq & \left\|x_{n}-x^{*}\right\|^{2}-g_{1}\left(\left\|z_{n}-y_{n}+x^{*}-y^{*}\right\|\right)-g_{2}\left(\left\|x_{n}-z_{n}-\left(x^{*}-y^{*}\right)\right\|\right) \\
& +2 \rho_{1}\left\|\left(\Psi_{1}+\Phi_{1}\right) z_{n}-\left(\Psi_{1}+\Phi_{1}\right) y^{*}\right\|\left\|y_{n}-x^{*}\right\|+2 \rho_{2} \|\left(\Psi_{2}+\Phi_{2}\right) x_{n} \\
& -\left(\Psi_{2}+\Phi_{2}\right) x^{*}\left|\left\|\mid z_{n}-\gamma^{*}\right\| .\right.
\end{aligned}
$$

And, then substituting (3.33) into (3.29), we obtain

$$
\begin{aligned}
\left\|x_{n+1}-x^{*}\right\|^{2} \leq & \beta_{n}\left\|x_{n}-x^{*}\right\|^{2}+\left(1-\beta_{n}\right)\left\{\left\|x_{n}-x^{*}\right\|^{2}-g_{1}\left(\left\|z_{n}-y_{n}+x^{*}-\gamma^{*}\right\|\right)\right. \\
& -g_{2}\left(\left\|x_{n}-z_{n}-\left(x^{*}-\gamma^{*}\right)\right\|\right) \\
& +2 \rho_{1}\left\|\left(\Psi_{1}+\Phi_{1}\right) z_{n}-\left(\Psi_{1}+\Phi_{1}\right) \gamma^{*}\right\|\left\|y_{n}-x^{*}\right\|+2 \rho_{2} \|\left(\Psi_{2}+\Phi_{2}\right) x_{n} \\
& \left.-\left(\Psi_{2}+\Phi_{2}\right) x^{*}\|\| z_{n}-\gamma^{*} \|\right\} \\
& +2 \alpha_{n}\left(1-\beta_{n}\right)\left\|\gamma V x_{n}-\mu F x^{*} \mid\right\| u_{n}-x^{*} \| \\
\leq & \left\|x_{n}-x^{*}\right\|^{2}-\left(1-\beta_{n}\right)\left\{g_{1}\left(\left\|z_{n}-y_{n}+x^{*}-\gamma^{*}\right\|\right)-g_{2}\left(\left\|x_{n}-z_{n}-\left(x^{*}-\gamma^{*}\right)\right\|\right)\right\} \\
& +2 \rho_{1}\left\|\left(\Psi_{1}+\Phi_{1}\right) z_{n}-\left(\Psi_{1}+\Phi_{1}\right) \gamma^{*}\right\|\left\|y_{n}-x^{*}\right\|+2 \rho_{2} \|\left(\Psi_{2}+\Phi_{2}\right) x_{n} \\
& -\left(\Psi_{2}+\Phi_{2}\right) x^{*} \mid\left\|z_{n}-\gamma^{*}\right\| \\
& +2 \alpha_{n}\left(1-\beta_{n}\right)\left\|\gamma V x_{n}-\mu F x^{*}\right\|\left\|u_{n}-x^{*}\right\|,
\end{aligned}
$$


which in turn implies that

$$
\begin{aligned}
\left(1-\beta_{n}\right)\{ & \left.g_{1}\left(\left\|z_{n}-y_{n}+x^{*}-\gamma^{*}\right\|\right)+g_{2}\left(\left\|x_{n}-z_{n}-\left(x^{*}-\gamma^{*}\right)\right\|\right)\right\} \\
\leq & \left\|x_{n}-x^{*}\right\|^{2}-\left\|x_{n+1}-x^{*}\right\|^{2}+2 \rho_{1}\left\|\left(\Psi_{1}+\Phi_{1}\right) z_{n}-\left(\Psi_{1}+\Phi_{1}\right)\right\| y_{n}-x^{*} \| \\
& +2 \rho_{2}\left\|\left(\Psi_{2}+\Phi_{2}\right) x_{n}-\left(\Psi_{2}+\Phi_{2}\right) x^{*}\right\|\left\|z_{n}-\gamma^{*}\right\|+2 \alpha_{n}\left(1-\beta_{n}\right)\left\|\gamma V x_{n}-\mu F x^{*}\right\|\left\|u_{n}-x^{*}\right\| \\
\leq & \left(\left\|x_{n}-x^{*}\right\|+\left\|x_{n+1}-x^{*}\right\|\right)\left\|x_{n+1}-x_{n}\right\|+2 \rho_{1}\left\|\left(\Psi_{1}+\Phi_{1}\right) z_{n}-\left(\Psi_{1}+\Phi_{1}\right) \gamma^{*}\right\| y_{n}-x^{*} \| \\
& +2 \rho_{2}\left\|\left(\Psi_{2}+\Phi_{2}\right) x_{n}-\left(\Psi_{2}+\Phi_{2}\right) x^{*}\right\|\left\|z_{n}-\gamma^{*}\right\|+2 \alpha_{n}\left(1-\beta_{n}\right)\left\|\gamma V x_{n}-\mu F x^{*}\right\|\left\|u_{n}-x^{*}\right\| .
\end{aligned}
$$

Since $\lim \inf _{n \rightarrow \infty}\left(1-\beta_{n}\right)>0,\left\|x_{n+1}-x_{n}\right\| \rightarrow 0, \alpha_{n} \rightarrow 0$ and (3.30), we have

$$
\lim _{n \rightarrow \infty} g_{1}\left(\left\|z_{n}-y_{n}+x^{*}-y^{*}\right\|\right)=\lim _{n \rightarrow \infty} g_{2}\left(\left\|x_{n}-z_{n}-\left(x^{*}-y^{*}\right)\right\|\right)=0 .
$$

It follows from the properties of $g_{1}$ and $g_{2}$ that

$$
\lim _{n \rightarrow \infty}\left\|z_{n}-y_{n}+x^{*}-y^{*}\right\|=\lim _{n \rightarrow \infty}\left\|x_{n}-z_{n}-\left(x^{*}-y^{*}\right)\right\|=0 .
$$

Consequently, we have

$$
\left\|x_{n}-y_{n}\right\| \leq\left\|x_{n}-z_{n}-\left(x^{*}-y^{*}\right)\right\|+\left\|z_{n}-y_{n}+x^{*}-y^{*}\right\| \rightarrow 0 \text { as } n \rightarrow \infty .
$$

On the other hand, we observe that

$$
\begin{aligned}
\left\|x_{n}-T\left(t_{n}\right) x_{n}\right\| & \leq\left\|x_{n}-T\left(t_{n}\right) y_{n}\right\|+\left\|T\left(t_{n}\right) y_{n}-T\left(t_{n}\right) x_{n}\right\| \\
& \leq\left\|x_{n}-T\left(t_{n}\right) y_{n}\right\|+\left\|y_{n}-x_{n}\right\| .
\end{aligned}
$$

From (3.24) and (3.34), we obtain that

$$
\lim _{n \rightarrow \infty}\left\|x_{n}-T\left(t_{n}\right) x_{n}\right\|=0 .
$$

For all $h>0$, we note that

$$
\begin{aligned}
\left\|x_{n}-T(h) x_{n}\right\| & \leq\left\|x_{n}-T\left(t_{n}\right) x_{n}\right\|+\left\|T\left(t_{n}\right) x_{n}-T(h) T\left(t_{n}\right) x_{n}\right\|+\left\|T(h) T\left(t_{n}\right) x_{n}-T(h) x_{n}\right\| \\
& \leq 2\left\|x_{n}-T\left(t_{n}\right) x_{n}\right\|+\left\|T\left(t_{n}\right) x_{n}-T(h) T\left(t_{n}\right) x_{n}\right\| .
\end{aligned}
$$

Since $\{T(h): h>0\}$ is a u.a.r. nonexpansive semigroup, it follows from (3.20) and (3.35) that

$$
\lim _{n \rightarrow \infty}\left\|x_{n}-T(h) x_{n}\right\|=0 .
$$

Since $\{T(h): h>0\}$ is a u.a.r. nonexpansive semigroup, by Lemma 2.13, for each $x \in$ $C$, there exists a sequence $\left\{T\left(t_{k}\right): t_{k}>0, k \in \mathbb{N}\right\}\{T(h): h>0\}$ such that $\left\{T\left(t_{k}\right) x\right\}$ converges strongly to some point in Fix $(\mathcal{S})$, where $t_{k} \rightarrow \infty$ as $k \rightarrow \infty$. Define a mapping $T: C \rightarrow C$ by

$$
T x=\lim _{k \rightarrow \infty} T\left(t_{k}\right) x, \quad \forall x \in C .
$$

By [25, Remark 3.4], we see that the mapping $T$ is nonexpansive such that Fix $(\mathrm{T})=\operatorname{Fix}(\mathcal{S})$. From (3.36), we obtain that

$$
\begin{aligned}
\lim _{n \rightarrow \infty}\left\|x_{n}-T x_{n}\right\| & =\lim _{n \rightarrow \infty} \lim _{k \rightarrow \infty}\left\|x_{n}-T\left(t_{k}\right) x_{n}\right\| \\
& =\lim _{k \rightarrow \infty} \lim _{n \rightarrow \infty}\left\|x_{n}-T\left(t_{k}\right) x_{n}\right\|=0 .
\end{aligned}
$$

Define a mapping $W: C \rightarrow C$ by

$$
W x=\delta T x+(1-\delta) G x, \quad \forall x \in C,
$$


where $\delta$ is a constant in $(0,1)$. By Lemma 2.11, we see that the mapping $W$ is nonexpansive such that

$$
\operatorname{Fix}(W)=\operatorname{Fix}(T) \cap \operatorname{Fix}(G)
$$

Notice that

$$
\begin{aligned}
\left\|x_{n}-W x_{n}\right\| & \leq\left\|\delta\left(x_{n}-T x_{n}\right)+(1-\delta)\left(x_{n}-G x_{n}\right)\right\| \\
& =\left\|\delta\left(x_{n}-T x_{n}\right)+(1-\delta)\left(x_{n}-y_{n}\right)\right\| \\
& \leq \delta\left\|x_{n}-T x_{n}\right\|+(1-\delta)\left\|x_{n}-y_{n}\right\| .
\end{aligned}
$$

From (3.34) and (3.37), we obtain that

$$
\lim _{n \rightarrow \infty}\left\|x_{n}-W x_{n}\right\|=0 .
$$

Next, we show that

$$
\lim \sup _{n \rightarrow \infty}\left\langle\gamma \sqrt{x}-\mu F \widehat{x}, j\left(u_{n}-\widehat{x}\right)\right\rangle \leq 0,
$$

where $\widehat{x}=\lim _{t \rightarrow 0} x_{t}$ and $x_{t}$ is the unique fixed point of the contraction mapping $T_{t}$ : $C \rightarrow C$ given by

$$
T_{t} x=Q_{C}[t \gamma V x+(I-t \mu F) W x], \quad \forall x \in C \text { and } t \in\left(0, \min \left\{1, \frac{1}{\tau}\right\}\right) .
$$

By Lemma 3.1, we have $\widehat{x} \in \operatorname{Fix}(W)=\Omega$, which solves the variational inequality

$$
\langle(\mu F-\gamma V) \widehat{x}, j(\widehat{x}-v)\rangle \leq 0, \quad \forall v \in \Omega .
$$

By (3.21) and Lemma 3.2, we obtain that

$$
\begin{aligned}
\lim \sup _{n \rightarrow \infty}\left\langle\gamma V \widehat{x}-\mu F \widehat{x}, j\left(u_{n}-\widehat{x}\right)\right\rangle & =\limsup _{n \rightarrow \infty}\left\langle\gamma \sqrt{x}-\mu F \widehat{x}, j\left(x_{n}-\widehat{x}\right)\right\rangle \\
& \leq 0 .
\end{aligned}
$$

Finally, we show that $x_{n} \rightarrow \widehat{x}$ as $n \rightarrow \infty$. Notice that $u_{n}=Q_{C} v_{n}$, where $v_{n}=\alpha_{n} \gamma V x_{n}$ $+\left(I-\alpha_{n} \mu F\right) T\left(t_{n}\right) y_{n}$. Then, from Lemma 2.6(c), we have

$$
\begin{aligned}
\left\|u_{n}-\widehat{x}\right\|^{2}= & \left\langle v_{n}-\widehat{x}, j\left(u_{n}-\widehat{x}\right)\right\rangle+\left\langle Q_{C} v_{n}-v_{n}, j\left(Q_{C} v_{n}-\widehat{x}\right)\right\rangle \\
\leq & \left\langle v_{n}-\widehat{x}, j\left(u_{n}-\widehat{x}\right)\right\rangle \\
= & \alpha_{n} \gamma\left\langle V x_{n}-V \widehat{x}, j\left(u_{n}-\widehat{x}\right)\right\rangle+\alpha_{n}\left\langle\gamma V \widehat{x}-\mu F \widehat{x}, j\left(u_{n}-\widehat{x}\right)\right\rangle \\
& +\left\langle\left(I-\alpha_{n} \mu F\right)\left(T\left(t_{n}\right) y_{n}-\widehat{x}\right), j\left(u_{n}-\widehat{x}\right)\right\rangle \\
\leq & \left(1-(\tau-\gamma L) \alpha_{n}\left(1-\beta_{n}\right)\right)\left\|x_{n}-\widehat{x}\right\|^{2}+\alpha_{n}\left\langle\gamma V \widehat{x}-\mu F \widehat{x}, j\left(u_{n}-\widehat{x}\right)\right\rangle .
\end{aligned}
$$

It follows from (3.40) that

$$
\begin{aligned}
\left\|x_{n+1}-\widehat{x}\right\|^{2} \leq & \beta_{n}\left\|x_{n}-\widehat{x}\right\|^{2}+\left(1-\beta_{n}\right)\left\|u_{n}-\widehat{x}\right\|^{2} \\
\leq & \beta_{n}\left\|x_{n}-\widehat{x}\right\|^{2}+\left(1-\beta_{n}\right)\left\{\left(1-(\tau-\gamma L) \alpha_{n}\left(1-\beta_{n}\right)\right)\left\|x_{n}-\widehat{x}\right\|^{2}\right. \\
& \left.+\alpha_{n}\left\langle\gamma \sqrt{x}-\mu F \widehat{x}, j\left(u_{n}-\widehat{x}\right)\right\}\right\} \\
= & \left(1-(\tau-\gamma L) \alpha_{n}\left(1-\beta_{n}\right)\right)\left\|x_{n}-\widehat{x}\right\|^{2}+\alpha_{n}\left(1-\beta_{n}\right)\left\langle\gamma V \widehat{x}-\mu F \widehat{x}, j\left(u_{n}-\widehat{x}\right)\right\rangle .
\end{aligned}
$$

Put $\sigma_{n}:=(\tau-\gamma L) \alpha_{n}\left(1-\beta_{n}\right)$ and $\delta_{n}:=\alpha_{n}\left(1-\beta_{n}\right)\left\langle\gamma \sqrt{x}-\mu F \widehat{x}, j\left(u_{n}-\widehat{x}\right)\right\rangle$. Then (3.41) re-duces to formula

$$
\left\|x_{n+1}-\widehat{x}\right\|^{2} \leq\left(1-\sigma_{n}\right)\left\|x_{n}-\widehat{x}\right\|^{2}+\delta_{n} .
$$


It is easily seen that $\sum_{n=1}^{\infty} \sigma_{n}=\infty$ and (using 3.39)

$$
\lim \sup _{n \rightarrow \infty} \frac{\delta_{n}}{\sigma_{n}}=\frac{1}{\tau-\gamma L} \lim \sup _{n \rightarrow \infty}\left\langle\gamma \sqrt{x}-\mu F \widehat{x}, j\left(u_{n}-\widehat{x}\right)\right\rangle \leq 0 .
$$

Hence, by Lemma 2.16, we conclude that $x_{n} \rightarrow \widehat{x}$ as $n \rightarrow \infty$. This completes the proof.

Remark 3.4. Note that Lemma 2.17 and Lemma 2.18 play an important role in the proof of Theorem 3.3. These are proved in the framework of the more general uniformly convex and 2-uniformly smooth Banach space. Lemma 2.17 is quite similar to the result of Yamada [10] which is obtained in a Hilbert space but we extended that result to a Banach space.

Remark 3.5. Theorem 3.3 extends the main result of Yao et al. [7] in the following ways:

(i) A general system of variational inequalities (1.12) containing two inverse-strongly accre-tive mappings are extends to a general system of nonlinear variational inequalities (1.15) containing perturbed mappings.

(ii) Theorem 3.3 for finding an element $\widehat{x} \in \operatorname{Fix}(\mathcal{S}) \cap \operatorname{Fix}(G)$ (G is defined as in Lemma 2.19) is more general the one of finding elements of $\widehat{x} \in V I\left(C, \Psi_{1}\right) \cap V I\left(C, \Psi_{2}\right)$ of Yao et al. [7].

Furthermore, our method of the proof is very different from that in [7, Theorem 3.7] because it can be applied to solving the problem of finding a common element of the set of common fixed points of a one-parameter nonexpansive semigroup and the set of solutions of a general system of nonlinear variational inequalities containing perturbed mappings.

From Theorem 3.3, Lemma 2.4 and Example 2.5, we have the following result.

Corollary 3.6. Let $C$ be a nonempty closed and convex subset of a real 2-uniformly smooth and uniformly convex Banach space $X$. Let $Q_{C}$ be a sunny nonexpansive retraction from $X$ onto $C$. Let $F: C \rightarrow X$ be a $\kappa$-Lipschitizian and $\eta$-strongly accretive operator with constants $\kappa, \eta>0, V: C \rightarrow C$ be an L-Lipschitzian mapping with a constant $L \geq 0$. Let $0<\mu<\frac{\eta}{\kappa^{2} K^{2}}$ and $0 \leq \gamma L<\tau$, where $\tau=\mu\left(\eta-\mu \kappa{ }^{2} K^{2}\right)$. Let $\mathcal{S}=\{T(h): h>0\}$ be a u.a.r. nonexpansive semigroup from $C$ into itself such that $\operatorname{Fix}(\mathcal{S}):=\cap_{h>0} \operatorname{Fix}(T(h)) \neq \emptyset$ and least there exists a $T(h)$ which is demicompact. Let $\Psi_{i}: C \rightarrow X(i=1,2)$ be $\widetilde{\beta}_{i}$-inverse-strongly accretive and $\Phi_{i}: C \rightarrow X(i=1,2)$ be $\tilde{\gamma}_{i}$ -inverse-strongly accretive. Assume that $\Omega:=\operatorname{Fix}(\mathcal{S}) \cap \operatorname{Fix}(G) \neq \emptyset$, where $G$ is defined as in Lemma 2.19. For given $x_{1} \in C$, let $\left\{x_{n}\right\}$ be a sequence defined by

$$
\left\{\begin{array}{l}
z_{n}=Q_{C}\left(x_{n}-\rho_{2}\left(\Psi_{2}+\Phi_{2}\right) x_{n}\right), \\
y_{n}=Q_{C}\left(z_{n}-\rho_{1}\left(\Psi_{1}+\Phi_{1}\right) z_{n}\right), \\
x_{n+1}=\beta_{n} x_{n}+\left(1-\beta_{n}\right) Q_{C}\left[\alpha_{n} \gamma V x_{n}+\left(I-\alpha_{n} \mu F\right) \frac{1}{t_{n}} \int_{0}^{t_{n}} T(s) y_{n} \mathrm{~d} s\right], \quad \forall n \geq 1,
\end{array}\right.
$$

where $\rho_{i} \in\left(0, \min \left\{\frac{\widetilde{\beta}_{i}}{2 K^{2}}, \frac{\tilde{\gamma}_{i}}{2 K^{2}}\right\}\right)$ for all $i=1$, 2. Suppose that $\left\{t_{n}\right\}$ is a positive real divergent sequence such that $\lim _{n \rightarrow \infty} \frac{t_{n}}{t_{n+1}}=1$, and $\left\{\alpha_{n}\right\},\left\{\beta_{n}\right\}$ are sequences in $[0,1]$ satisfying the following conditions: 
(C1) $\lim _{n \rightarrow \infty} \alpha_{n}=0$ and $\sum_{n=1}^{\infty} \alpha_{n}=\infty$;

(C2) $0<\lim \inf _{n \rightarrow \infty} \beta_{n} \leq \lim \sup _{n \rightarrow \infty} \beta_{n}<1$.

Then, the sequence $\left\{x_{n}\right\}$ defined by (3.42) converges strongly to $\widehat{x} \in \Omega$ as $n \rightarrow \infty$, which $\tilde{x}$ is the unique solution of the variational inequality

$$
\langle(\mu F-\gamma V) \widetilde{x}, j(\widetilde{x}-v)\rangle \leq 0, \quad \forall v \in \Omega,
$$

and $(\widehat{x}, \hat{y})$ is the solution of the problem (1.15), where $\hat{y}=Q_{C}\left(\widehat{x}-\rho_{2}\left(\Psi_{2}+\Phi_{2}\right) \widehat{x}\right)$.

\section{Acknowledgements}

The authors were supported by the Higher Education Research Promotion and National Research University Project of Thailand, Office of the Higher Education Commission (NRU-CSEC No.55000613).

\section{Authors' contributions}

PS and PK conceived the idea, designed the research and wrote the article; PS conducted the research. Both authors have read and approved the final manuscript.

\section{Competing interests}

The authors declare that they have no competing interests.

Received: 10 February 2012 Accepted: 11 June 2012 Published: 11 June 2012

\section{References}

1. Kinderlehrer, D, Stampacchia, G: An Introduction to Variational Inequalities and their Applications. Academic Press Inc., New York (1980)

2. Noor, MA: General variational inequalities and nonexpansive mappings. J Math Anal Appl. 331, 810-822 (2007). doi:10.1016/j.jmaa.2006.09.039

3. Yao, Y, Shahzad, N: New methods with perturbations for non-expansive mappings in Hilbert spaces. Fixed Point Theory Appl. 2011, 79 (2011). doi:10.1186/1687-1812-2011-79

4. Yao, Y, Shahzad, N: Strong convergence of a proximal point algorithm with general errors. Optim Lett. 6, 621-628 (2012). doi:10.1007/s11590-011-0286-2

5. Yao, Y, Liou, YC, Chen, CP: Algorithms construction for nonexpansive mappings and inverse-strongly monotone mappings. Taiwan J Math. 15, 1979-1998 (2011)

6. Yao, Y, Chen, R, Liou, YC: A unified implicit algorithm for solving the triple-hierarchical constrained optimization problem. Mathematical and Computer Modelling. 55, 1506-1515 (2012). doi:10.1016/..mcm.2011.10.041

7. Yao, Y, Liou, Y-C, Kang, SM, Yu, Y: Algorithms with strong convergence for a system of nonlinear variational inequalities in Banach spaces. Nonlinear Anal Theory Method Appl. 74,6024-6034 (2011). doi:10.1016/j.na.2011.05.079

8. Yao, Y, Liou, Y-C, Kang, SM: Two-step projection methods for a system of variational inequality problems in Banach spaces. J Glob Optim. doi: 10.1007/s10898-011-9804-0

9. Takahashi, W: Nonlinear functional analysis. Yokohama Publishers, Yokohama (2000)

10. Yamada, I: The hybrid steepest descent method for the variational inequality problems over the intersection of fixed point sets of nonexpansive mappings. In: Butnariu, D, Censor, Y, Reich, S (eds.) Inherently Parallel Algorithms in Feasibility and Optimization and Their applications. Studies in Computational Mathematics, vol. 8, pp. 473-504. NorthHolland, Amsterdam (2001)

11. Marino, G, Xu, HK: A general iterative method for nonexpansive mappings in Hilbert spaces. J Math Anal Appl. 318, 43-52 (2006). doi:10.1016/j.jmaa.2005.05.028

12. Tian, M: A general iterative algorithm for nonexpansive mappings in Hilbert spaces. Nonlinear Anal Theory Methods Appl. 73, 689-694 (2010). doi:10.1016/j.na.2010.03.058

13. Yao, Y, Noor, MA, Noor, Kl, Liou, YC: Modified extragradient methods for a system of variational inequalities in Banach spaces. Acta Appl Math. 110, 1211-1224 (2010). doi:10.1007/s10440-009-9502-9

14. Browder, FE: Nonexpansive nonlinear operators in a Banach space. Proc Natl Acad Sci USA. 54(4), 1041-1044 (1965). doi:10.1073/pnas.54.4.1041

15. Aleyner, A, Censor, Y: Best approximation to common fixed points of a semigroup of nonexpansive operator. Nonlinear Convex Anal. 6(1), 137-151 (2005)

16. Aleyner, A, Reich, S: An explicit construction of sunny nonexpansive retractions in Banach spaces. Fixed Point Theory Appl. 2005(3), 295-305 (2005)

17. Benavides, TD, Acedo, GL, Xu, HK: Construction of sunny nonexpansive retractions in Banach spaces. Bull Austr Math Soc. 66(1), 9-16 (2002). doi:10.1017/S0004972700020621

18. Chen, $\mathrm{R}$, Song, $\mathrm{Y}$ : Convergence to common fixed point of nonexpansive semigroup. J Comput Appl Math. 200 566-575 (2007). doi:10.1016/j.cam.2006.01.009

19. Reich, S: Asymptotic behavior of contractions in Banach spaces. J Math Anal Appl. 44, 57-70 (1973). doi:10.1016/0022 247X(73)90024-3

20. Kitahara, S, Takahashi, W: Image recovery by convex combinations of sunny nonexpansive retractions. Topol Methods Nonlinear Anal. 2, 333-342 (1993)

21. Xu, HK: Inequalities in Banach spaces with applications. Nonlinear Anal Theory Methods Appl. 16, 1127-1138 (1991). doi:10.1016/0362-546X(91)90200-K 
22. Lu, LS: Ishikawa and Mann iterative processes with errors for nonlinear strongly accretive mappings in Banach spaces. J Math Anal Appl. 194, 114-125 (1995). doi:10.1006/jmaa.1995.1289

23. Suzuki, T: Strong convergence of Krasnoselskii and Mann's type sequence for one-parameter nonexpansive semigroup without Bochner integrals. J Math Anal Appl. 305, 227-239 (2005). doi:10.1016/j.jmaa.2004.11.017

24. Bruck, RE: Properties of fixed point sets of nonexpansive mappings in Banach spaces. Trans Am Math Soc. 179, 251-262 (1973)

25. Nan Li, X, Gu, JS: Strong convergence of modified Ishikawa iteration for nonexpansive semigroup in Banach space. Nonlinear Anal Theory Methods Appl. 73, 1085-1092 (2010). doi:10.1016/j.na.2010.04.040

26. Browder, FE: Nonexpansive nonlinear operators in a Banach space. Proc Natl Acad Sci USA. 54, 1041-1044 (1965). doi:10.1073/pnas.54.4.1041

27. Kamimura, S, Takahashi, W: Strong convergence of a proximal-type algorithm in a Banach space. SIAM J Optim. 13, 938-945 (2002). doi:10.1137/S105262340139611X

28. Xu, HK: Iterative algorithms for nonlinear operators. J Lond Math Soc. 66(1), 240-256 (2002). doi:10.1112/ S0024610702003332

29. Jung, JS: Some algorithms for finding fxed points and solutions of variational inequalities. Abstr Appl Anal 2012, 16 (2012). (Article ID 153456)

30. Cholamjiak, P: A hybrid iterative scheme for equilibrium problems, variational inequality problems, and fixed point problems in Banach spaces. Fixed Point Theory Appl 2009, 18 (2009). (Article ID 719360)

31. Cholamijak, P, Suantai, S: A new hybrid algorithm for variational inclusions, generalized equilibrium problems and a finite family of quasi-nonexpansive mappings. Fixed Point Theory Appl 2009, 20 (2009). (Article ID 350979)

doi:10.1186/1029-242X-2012-133

Cite this article as: Sunthrayuth and Kumam: Iterative algorithms approach to a general system of nonlinear variational inequalities with perturbed mappings and fixed point problems for nonexpansive semigroups. Journal of Inequalities and Applications 2012 2012:133.

\section{Submit your manuscript to a SpringerOpen ${ }^{\odot}$} journal and benefit from:

- Convenient online submission

- Rigorous peer review

- Immediate publication on acceptance

- Open access: articles freely available online

- High visibility within the field

- Retaining the copyright to your article

Submit your next manuscript at $\gg$ springeropen.com 